\title{
Article \\ Effectiveness of Hybrid Fibers on the Fracture and Shear Behavior of Prestressed Concrete Beams
}

\author{
Chandrashekhar Lakavath ${ }^{1}$ (D), Aniket B. Bhosale ${ }^{1}$, S. Suriya Prakash ${ }^{1}$ (D) and Akanshu Sharma ${ }^{2, *(D)}$ \\ 1 Department of Civil Engineering, Indian Institute of Technology Hyderabad, Sangareddy 502285, India; \\ ce19resch11007@iith.ac.in (C.L.); ce16mtech11027@iith.ac.in (A.B.B.); suriyap@ce.iith.ac.in (S.S.P.) \\ 2 Lyles School of Civil Engineering, Purdue University, West Lafayette, IN 47907, USA \\ * Correspondence: akanshu@purdue.edu
}

check for updates

Citation: Lakavath, C.; Bhosale, A.B.; Prakash, S.S.; Sharma, A.

Effectiveness of Hybrid Fibers on the

Fracture and Shear Behavior of

Prestressed Concrete Beams. Fibers

2022, 10, 26. https://doi.org/

$10.3390 /$ fib10030026

Academic Editor: Martin J. D. Clift

Received: 16 January 2022

Accepted: 1 March 2022

Published: 8 March 2022

Publisher's Note: MDPI stays neutral with regard to jurisdictional claims in published maps and institutional affiliations.

Copyright: (C) 2022 by the authors. Licensee MDPI, Basel, Switzerland. This article is an open access article distributed under the terms and conditions of the Creative Commons Attribution (CC BY) license (https:/ / creativecommons.org/licenses/by/ $4.0 /)$.

\begin{abstract}
This study investigates the effectiveness of hybrid fibers (steel and macro-synthetic) on the shear behavior of prestressed concrete beams. The hybrid fiber combination was selected to avoid workability issues at high volume dosages and ensure effective crack arresting over the crack opening range. Fracture studies included testing notched concrete prisms to identify the role of hybrid fibers in the crack bridging mechanism. Seven hybrid fiber reinforced prestressed concrete (HFRPC) beams were tested at a low shear span (a) to depth (d) ratio of 2.4. The effects of hybrid fibers on load-deflection behavior and strain in the strand are reported. Similarly, the crack opening, crack slip and crack angle variation regarding applied shear were investigated using the digital image correlation (DIC) technique. Test results of HFRPC beams showed considerable improvements in peak load and the post-peak response with a higher hybrid fiber dosage. The crack opening and crack slip measurement across the major shear crack revealed continuous dilatant behavior. The kinematic response of critical shear crack reflects the sustained dilation response up to the ultimate load, which depends on the critical shear crack angle of the tested beams. As the fiber dosage increases, the shear crack slip and width are reduced, indicating the roles of hybrid fibers in improving ductility and the change in failure mode from brittle shear tension to relatively ductile shear tension.
\end{abstract}

Keywords: crack kinematics; fracture energy; hybrid fibers; prestressed concrete beams; shear

\section{Introduction}

Concrete beams can be very brittle if not adequately reinforced. The addition of discrete and randomly oriented fiber reinforcements in concrete helps to improve its ductility under shear loads. This study focuses on the effects of hybrid combinations of steel fibers (SF) and polyolefin (PO)-based macro-synthetic fibers (MSF), on the shear behavior of prestressed concrete beams. Ensuring adequate ductility is an essential design aspect of reinforced concrete (RC) and prestressed concrete (PSC) beams. However, the prestressed concrete beam's ductile behavior and failure modes depend on different parameters, such as the compressive strength of the concrete, the longitudinal reinforcement ratio, the web reinforcement ratio, and the level of prestressing. Based on previous studies, such as Kani's classical theory [1], the shear span to depth ratio $(a / d)$ of 2.5 is considered a pivot point, below which the reinforced concrete $(\mathrm{RC})$ beams fail in a shear critical mode. Strut action or arch action is possible in RC beams tested at very low $a / d$ ratios $(a / d<1.5)$ [2]. Similarly, for $a / d$ ratios between 2.5 and 6, possible failures occur via flexure shear mode due to diagonal shear tension after flexure cracking. Therefore, in this study, a shear span to depth ratio $(a / d)$ of 2.4 was considered to avoid arch action and ensure the diagonal shear tension (DST) mode in prestressed concrete beams [3-6].

Hybrid fiber combinations can be made using the same fibers with different geometrical properties or by combining different types of fibers with various physical and mechanical properties. In general, steel fibers are the most popular type for enhancing the mechanical properties of concrete, whereas non-metallic fibers are used to enhance other 
physical properties. This study used a combination of steel fibers (SF) and macro-synthetic fibers (MSF) for hybrid combinations. In recent years, the beneficial effects of hybrid fiber reinforced concrete (HFRC) on various properties of concrete, such as mechanical, thermal, and shielding properties, have been investigated by many researchers [7-10]. Incorporating two or more fibers may significantly improve the concrete's fracture behavior by enhancing the toughness and tensile strength [11-15]. One of the main reasons for using hybrid fiber combinations incorporating characteristics such as various elasticity moduli, is to control the crack opening at various levels [16]. By mixing more than two types and sizes of fibers, the tensile properties of concrete can be altered, even to achieve strain hardening behavior [17]. Relatively few studies have focused on shear crack propagation analysis of hybrid fiber reinforced prestressed concrete beams, using the digital image correlation (DIC) technique $[18,19]$. The use of the DIC technique helped us better understand the shear dilatancy behavior, which was the primary focus of this study. In HFRC, the constituent fibers enhance the material's properties at various concrete fracture stages, such as pre-macro cracking and post-macro cracking stages. The addition of macro-synthetic fibers (MSF) can reduce the balling effect and workability issues associated with steel fibers. They can also improve fracture toughness, ductility, residual strength, impact resistance and the synergy effect $[13,20-22]$.

Only a few researchers in the past have investigated the effects of hybrid fibers on the response of structural elements under shear stress [23-25]. The prestressing force increases the cracking strength, decreases the angle of the compression strut and reduces the shear strain in the stirrups. The shear resistance in prestressed concrete beam consists of contributions from (a) un-cracked concrete, (b) aggregate interlock, (c) the resistance of fibers bridging the crack, (d) dowel action of longitudinal reinforcement, (e) amount of pre-compression (prestress) and (f) stirrups [26-30]. Understanding shear crack kinematics is essential for developing a rational, analytical model for predicting the shear capacity of fiber-reinforced prestressed concrete beams. A significant improvement is possible in the early fracture response of concrete containing a hybrid fiber blend after macro-synthetic fiber addition [16,31]. Shear studies of prestressed steel fiber reinforced concrete beams have been performed in the past $[26,32,33]$. However, the particulars of the shear behavior of prestressed hybrid fiber reinforced concrete beams are mainly unknown.

\section{Research Significance and Objectives}

This research aimed to fill the current knowledge gap by investigating the shear behavior of prestressed hybrid fiber reinforced concrete. Prestressed concrete beams were cast and tested to understand the influences of different volume fractions of hybrid fibers on their shear behavior. Notched beams with varying fiber dosages were tested under three-point bending to understand the Mode-I fracture behavior. In addition, concrete cubes and cylinders were tested to understand compression behavior. This study focuses on the effect of fiber dosage as a parameter. All other sectional parameters, such as longitudinal reinforcement ratio, prestressing force, cross-section details and compressive strength were kept constant. Therefore, the objectives of this study were limited to:

1. Understanding the variations in deformation characteristics and failure modes of prestressed concrete beams due to hybrid fibers.

2. Studying the influences of different volume fractions of hybrid fibers on crack kinematics, such as crack opening $\left(U_{w}\right)$ and crack slip $\left(U_{s}\right)$.

3. Analyzing the effects of hybrid fiber reinforcement on fracture energy and the crack arresting mechanism in Mode-I fractures, and the latter's inter-relation with the shear behavior of prestressed concrete beams.

\section{Materials and Methods}

The concrete mix was designed to achieve a target cubic compressive strength of $45 \mathrm{MPa}$ for casting prisms (notched beams) and prestressed concrete beams (PSC). Cubes of size $150 \mathrm{~mm}$ and prisms of size $150 \mathrm{~mm} \times 150 \mathrm{~mm} \times 500 \mathrm{~mm}$ were cast to study the 
compressive strength of the concrete mixes and the fracture behavior of the mix. The measured mean compressive strength $\left(f_{\mathrm{cm}}\right)$ of plain concrete was $45.30 \mathrm{MPa}$. The types of fibers (steel and poly-olefin-based macro-synthetic fibers) used in this experimental program and their mechanical properties are shown in Table 1. The PSC beams of dimensions $300 \mathrm{~mm} \times 150 \mathrm{~mm} \times 1600 \mathrm{~mm}$ were cast to study the influences of fibers on shear resistance. The secondary reinforcements $8 \mathrm{~mm}$ in diameter with a spacing of $150 \mathrm{~mm}$ were provided in the noninterest region (Figure 1) to restrict the failure in the test zone.

Table 1. Properties of fibers and prestressing strand.

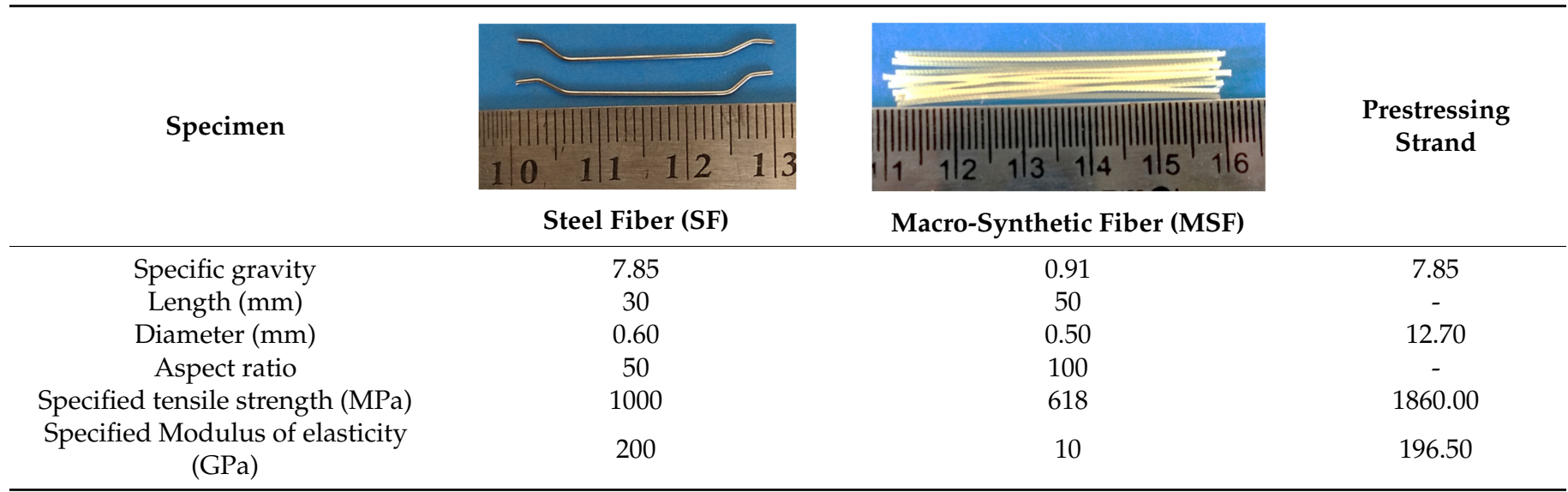

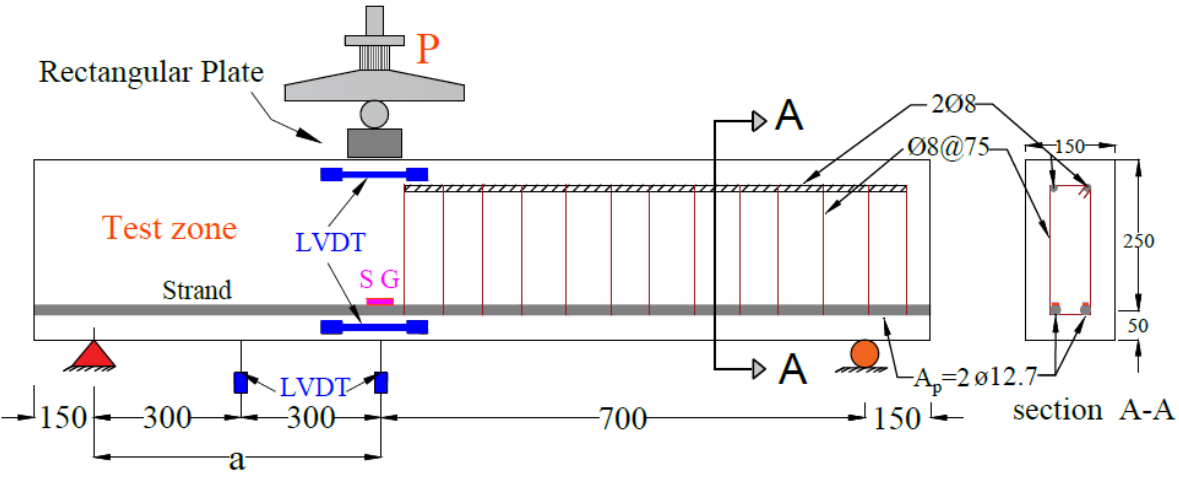

Figure 1. Hybrid fiber reinforced prestressed concrete beam and test setup details. $\mathrm{P}=$ applied load, $\mathrm{SG}=$ Strain gauge, $\mathrm{A}-\mathrm{A}=$ cross section view .

The specimens were named based on the volume fractions $\left(V_{f}\right)$ of fibers added to the total concrete volume. Hybrid fibers are mixtures of equal volumes of hooked end steel fibers (SF) and polyolefin (PO) macro-synthetic fibers. For example, HB50 indicates the combination of $0.25 \% V_{f}$ of SF and $0.25 \% V_{f}$ of PO fibers. The details of the quantities of ingredients, such as cement, coarse aggregate, fine aggregates, superplasticizers, and fibers used in the concrete mixes, are listed in Table 2. All the materials were added in the following sequence to avoid the balling effect in fiber reinforced concrete. In these mixes, the full quantities of coarse aggregates, fine aggregate, and cement were added, followed by $50 \%$ of the total water quantity. Then, steel and macro-synthetic fibers were added manually, and the remaining water and superplasticizers were added to the pan mixture [34]. The variations in compressive strength measured with the standard cubes due to fiber addition are summarized in Table 3. The compressive strength increased by $4.2 \%$, $14.1 \%$, and $23.8 \%$ for HB50, HB100, and HB150, respectively (increasing portions of fiber). 
Table 2. Concrete mix design quantities in $\mathrm{kg} / \mathrm{m}^{3}$.

\begin{tabular}{|c|c|c|c|c|c|c|c|c|c|}
\hline \multirow{2}{*}{ Mix ID } & \multirow{2}{*}{$\mathrm{C}$} & \multirow{2}{*}{ CSS } & \multirow{2}{*}{ NRS } & \multirow{2}{*}{ SP } & \multirow{2}{*}{ Water } & \multicolumn{2}{|c|}{ CA } & \multicolumn{2}{|c|}{ Hybrid Fiber Combination } \\
\hline & & & & & & $20 \mathrm{~mm}$ & $10 \mathrm{~mm}$ & SF & PO \\
\hline HB00 & 450 & 415 & 312 & 2.6 & 152 & 755 & 355 & 0 & 0 \\
\hline HB50 & 450 & 415 & 312 & 2.6 & 152 & 755 & 355 & 19.65 & 2.27 \\
\hline HB100 & 450 & 415 & 312 & 2.6 & 152 & 755 & 355 & 39.25 & 4.55 \\
\hline HB150 & 450 & 415 & 312 & 2.6 & 152 & 755 & 355 & 58.87 & 2.27 \\
\hline
\end{tabular}

Note: $\mathrm{C}=$ cement, $\mathrm{CSS}=$ crushed stone sand, $\mathrm{NRS}=$ natural river sand, $\mathrm{SP}=$ super plasticizer, $\mathrm{CA}=$ coarse aggregate.

Table 3. Summary of material characteristics of concrete.

\begin{tabular}{|c|c|c|c|c|c|c|c|c|c|c|c|}
\hline \multirow{2}{*}{ Mix ID } & \multirow{2}{*}{$\begin{array}{c}f_{c m} \\
\text { (S.D) }\end{array}$} & \multicolumn{3}{|c|}{$\begin{array}{c}\text { Residual Flexural Tensile } \\
\text { Strength (MPa) }\end{array}$} & \multirow{2}{*}{$\begin{array}{c}\text { Total Fracture } \\
\text { Energy } \\
\mathrm{G}_{f}(\mathrm{~N} / \mathrm{mm})\end{array}$} & \multirow{2}{*}{$\Delta \mathbf{G}_{f}=\frac{G_{f}}{G_{f c}}$} & \multicolumn{5}{|c|}{ Toughness $T_{f} \times 10^{-3}(\mathrm{kN}-\mathrm{mm})$} \\
\hline & & $\mathbf{f}_{\mathbf{R} 1}$ & $\mathbf{f}_{\mathrm{R} 3}$ & $\mathbf{f}_{\mathbf{R} 4}$ & & & I & II & III & IV & Total $\left(T_{f}\right)$ \\
\hline HB00 & $\begin{array}{l}45.30 \\
(1.73)\end{array}$ & 0.60 & - & - & 0.156 & 1.00 & 0.53 & 3.14 & - & - & 3.67 \\
\hline HB50 & $\begin{array}{l}47.21 \\
(1.52)\end{array}$ & 1.93 & 1.93 & 1.15 & 0.976 & 6.25 & 0.35 & 6.29 & 13.36 & 3.59 & 23.60 \\
\hline HB100 & $\begin{array}{l}51.70 \\
(1.63)\end{array}$ & 2.81 & 3.26 & 3.09 & 1.484 & 9.51 & 0.78 & 5.19 & 22.21 & 10.25 & 38.43 \\
\hline HB150 & $\begin{array}{l}56.12 \\
(1.80)\end{array}$ & 6.21 & 6.07 & 5.76 & 3.063 & 19.63 & 1.58 & 4.51 & 27.52 & 42.10 & 75.70 \\
\hline
\end{tabular}

Note: $f_{c m}=$ compressive strength $(\mathrm{MPa}), \Delta \mathrm{G}_{f}=$ ratio of fracture energy, $\mathrm{I}=$ peak load point, $\mathrm{II}=$ first load drop point, III = second peak point, IV = ultimate point.

Similarly, the average flexural tensile strength increased by $68.9 \%$ and $114.5 \%$ for HB50 and HB100 beams. The types of fibers and their mechanical properties used in the experimental program are detailed in Table 1 . The effect of steel fibers on the shear behavior of prestressed beams was previously studied by other authors [32]. Due to variations in the compressive strength of concrete, the behavior of specimens with only steel fibers could not be directly compared with the behavior of specimens with hybrid fiber dosages. In addition, a large volume of macro-synthetic fibers may be required for improving the shear performance of prestressed concrete under shear stress. The main reason for selecting the hybrid combination of fibers is that hybrid fibers provide excellent residual strength over a range of crack mouth opening displacements (CMOD) without compromising the workability during casting. Various researchers [16,32] discussed the advantages of a hybrid combination of fibers and their fracture behavior. Based on their investigation, it was concluded that hybrid fibers will improve the residual tensile strength without compromising workability.

\section{Results and Discussion}

The following sections discuss the hybrid fiber reinforced concrete beams behavior, such as fracture response, shear behavior, and code recommendation predictions.

\subsection{Fracture Behavior of Hybrid FRC Beams}

Three-point bending tests were performed on beams of size $150 \mathrm{~mm} \times 150 \mathrm{~mm} \times 500 \mathrm{~mm}$ to understand the contribution of hybrid fibers to bending (Figure 2a). According to the Japan concrete institute (JCI) [35] code, a notch of $25 \mathrm{~mm}$ depth and $5 \mathrm{~mm}$ width, as shown in Figure $2 \mathrm{a}$, was created in each beam. The testing was performed in displacement mode by controlling the crack mouth opening displacement (CMOD) at a rate of $0.05 \mathrm{~mm} / \mathrm{min}$ as per European standards (EN14651-2005) [36]. The flexural performance in terms of load versus CMOD, residual flexural tensile strength $\left(f_{R}\right)$, fracture energy $\left(G_{f}\right)$, and crack arresting behavior due to the addition of hybrid fibers is reported in the following sections. However, not many studies have focused on the shear behavior of hybrid fiber reinforced (macro-synthetic and steel fibers) PSC beams under shear stress. This study aimed to understand the role of hybrid fibers in fracture and shear behavior through digital image correlation (DIC) analysis. 


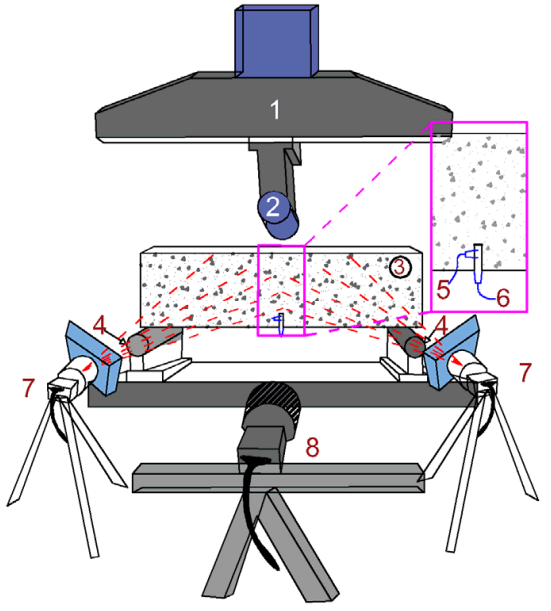

(a)

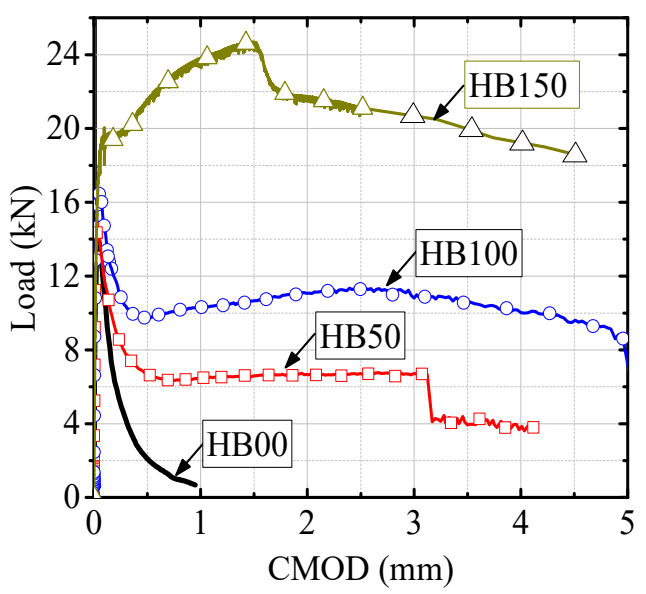

(b)

Figure 2. Fracture test. (a) Fracture test setup. 1. Actuator. 2. Loading jig. 3. FRC specimen. 4. Roller supports. 5. CTOD gauge. 6. CMOD gauge. 7. Light source. 8. DIC camera. (b) Load versus CMOD.

Gustafsson and Hillerborg [37] introduced a parameter to associate the fracture energies with the shear capacities of the beams, called characteristic length. They concluded that the characteristic length parameter is proportional to the material's fracture energy $\left(G_{f}\right)$. Therefore, it is essential to understand the fracture energy variations of composite materials, such as HFRC. Foster et al. [38] estimated the shear capacities of SFRC beams by using the residual tensile strengths obtained from the inverse analysis. The tensile stress-strain response from the fracture test can be obtained from the multi-linear tensile stress-strain response proposed by Bhosale et al. [7,39]. The inter-relationship between the concrete matrix and fiber reinforcement components to shear capacity is shown in Figure 3. In this study, the residual tensile strengths obtained from the International Union of Laboratories and Experts in Construction Materials, Systems and Structures (RILEM) recommendations were used to estimate the shear capacities of HFRPC beams. The impacts of fiber volume fraction on crack arresting mechanism and fracture energy are discussed in detail in the following sections.

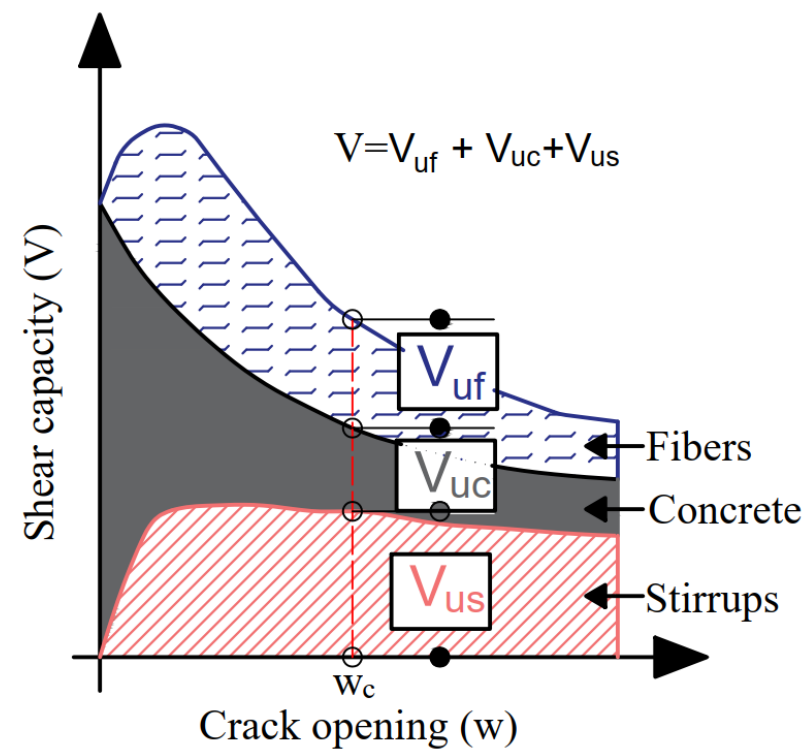

Figure 3. The interrelationship between concrete matrix, fibers, and reinforcement components in the determination of shear capacity [37]. $V_{u f}=$ fibers contribution, $V_{u c}=$ Concrete matrix contribution, $V_{u s}=$ Stirrups Contribution. 


\subsubsection{Residual Flexural Strength Calculations Using RILEM Recommendations}

The residual flexural tensile strength $\left(f_{R, i}\right)$ is typically used to estimate the fibers' contribution to the tensile resistance of FRC. It can be conservatively calculated as per RILEM [40] recommendations using Equation (1), which is derived assuming the linear elastic response of FRC in both compression and tension. From load-CMOD curves obtained from the tests on HFRC prisms, we observed that peak load did not increase significantly with the increase in fiber volume. The fiber contributes to the load-carrying mechanism soon after cracking the concrete. Thus, the crack is initiated only after reaching the peak load in all the prisms. However, the strength degradation is alleviated in the post-peak region due to the fibers' resistance towards crack propagation. The detailed investigation of crack propagation was carried out using the digital image correlation (DIC) technique at various points of load-CMOD curves, as shown in Figure 4a. In this experimental program, the highest flexural tensile strengths were observed in the range of 0 to $0.05 \mathrm{~mm}$ of CMOD.

$$
f_{R, i}=\frac{3 F_{R, i} L}{2 b^{\prime} h_{s p}^{2}}
$$

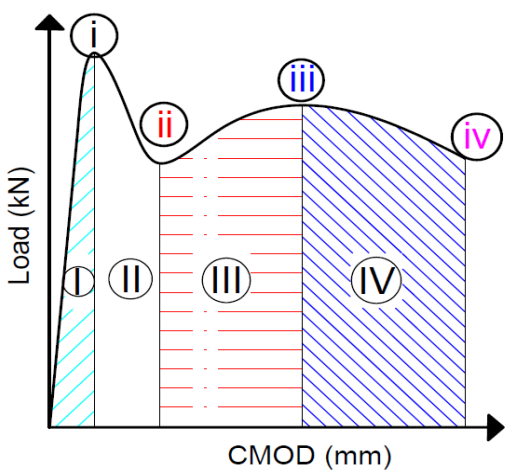

(a)

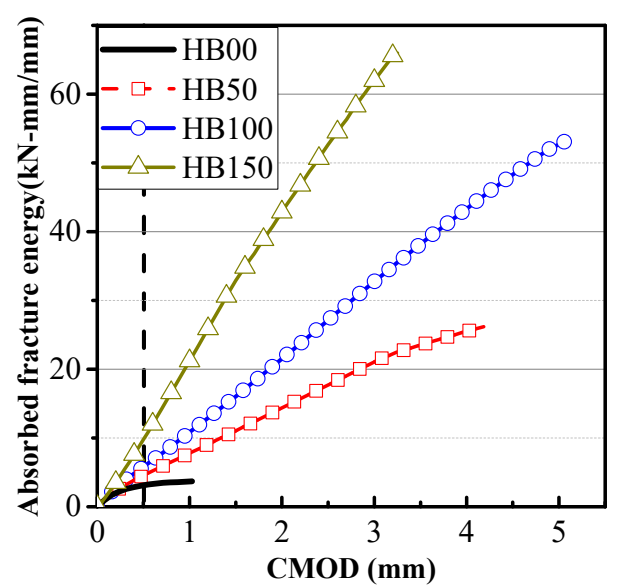

(b)

Figure 4. Fracture test results. (a) Schematic representation of considered points in load-CMOD curve. I = phases I, II = phases II, III = phases II, IV = phase IV, i = peak load, ii = fist load drop point, iii $=$ second peak load due to fibers, $\mathrm{iv}=$ ultimate load point $(\mathrm{CMOD}=3.5 \mathrm{~mm}) .(\mathbf{b})$ Absorbed fracture energy of $\mathrm{HB}$ notched beams.

The flexure tensile strengths at different points of load-CMOD curves were calculated and reported in Table 3. Test results show that the residual loads of prism beams at CMOD of $3 \mathrm{~mm}$ are $53 \%, 31.7 \%$, and $27.5 \%$ of the peak loads of HB50, HB100, and HB150 specimens. Higher residual strength indicates a more substantial contribution of fibers in stress redistribution and load resistance. The shear capacity calculations of HFRPC beams require residual tensile strength as an input parameter. The residual tensile strengths $f_{R 1}$ and $f_{R 4}$ were used to estimate the shear load resisting capacity of HFRPC beams using fib-MC2010 code provisions and RILEM recommendations.

\subsubsection{Fracture Energy Calculations Using JCI Provisions}

As per Japanese standards (JCI) [41], the fracture energies of control and hybrid fiber reinforced concrete prism specimens were calculated using Equations (2) and (3).

$$
\begin{gathered}
G_{f}=\frac{0.75 W_{o}+W_{1}}{A_{\text {lig }}} \\
W_{1}=0.75\left(\frac{S}{L} m_{1}+2 m_{2}\right) g \times C M O D_{c}
\end{gathered}
$$


According to JCI [35] code, the fracture energy $\left(G_{f}\right)$ calculated for the control specimen (HB00) was $0.156 \mathrm{~N} / \mathrm{mm}$. With the addition of fiber, the fracture energy increased significantly to 0.976 and $3.06 \mathrm{~N} / \mathrm{mm}$ for HB50 and HB150, respectively. The increase in $G_{f}$ due to the addition of hybrid fibers ranged from 6.25 to 19.63 times that of the control specimen (HB00), as shown in Table 3.

The fracture energy is the energy required to open a unit area of the crack surface. At certain stages in the load-CMOD response, the post-cracking parameters, such as crack length and strain redistribution of HB prisms, were evaluated. According to RILEM [40] recommendations, the CMOD of $0.5 \mathrm{~mm}$ is considered a serviceability limit. A higher CMOD value of $3.5 \mathrm{~mm}$ is the limit for the ultimate state. The variation in absorbed fracture energy with respect to CMOD is shown in Figure $4 \mathrm{~b}$. The energy required to open a CMOD of $0.01 \mathrm{~mm}$ is evaluated by calculating the area under the load-CMOD curve in equal intervals of $0.01 \mathrm{~mm} \mathrm{CMOD}$. It is represented as toughness $\left(T_{f}\right)$. The variation in absorbed fracture energy with respect to CMOD is illustrated in Figure $4 \mathrm{~b}$. Comparing fracture energy values also suggests not much variation in the cumulative fracture energy up to peak load for all the specimens. However, in the post-cracking regime, the cumulative absorbed fracture energy slopes increased with fiber volume fraction. No change in slope represents that the contribution of fibers to the energy dissipation capacity of HFRPC beams is minimal (HB50 compared to the control). In HB50 notched beams, the lesser quantity of fibers activated across the cracked plane to bridge the crack was not effective. Hence, the variations in the slope are not significant. In the case of HB100 and HB150 beams, the slope changes in cumulative absorbed fracture energy are substantial, signifying that fibers can significantly improve the ductility and change the failure mode (Figure $4 \mathrm{~b}$ ).

The tension stiffening response of fiber-reinforced concrete beams depends on many factors, such as length, diameter, aspect ratio, types of fiber, the volume fraction of fibers, concrete matrix strength, and aggregate size. In the past, few researchers [42-44] studied the influences of fiber orientation factors on mechanical performance indicators, such as strength, load-CMOD, and fracture energy. Considerable improvements can result from proper orientation, due to which the post-peak response of the fracture beam will increase $[42,45]$. An increment in the post-peak response of the load-CMOD curve leads to an increase in residual flexural tensile strength $\left(f_{R}\right)$. Then, the fiber-reinforced prestressed concrete beam ductility may increase in both flexure and shear dominant cases.

\subsubsection{Calibration of Digital Image Correlation (DIC) Results}

Non-contact full-field displacement measurements through the DIC technique were used to analyze the crack opening, crack slip, and crack propagation responses of prisms and HFRPC beams. The crack propagation can also be monitored using a standard video camera. However, the DIC technique is required to study the shear dilatancy of concrete members, such as variations in crack opening and crack slip with respect to the applied load. This relationship can be measured only with the full-field strain measurement in the test region. Using the measured data, the shear resistance through aggregate interlock can be calculated. All the beam surfaces were randomly speckled with acrylic-based white paint for proper DIC measurements. The images of the specimens were captured using a 5-megapixel camera and $50 \mathrm{~mm}$ lens. Adequate lighting of equal intensity was ensured on the test specimen to track the movement of the speckles. All the captured images were postprocessed using VIC-2D ${ }^{\mathrm{TM}}$ by Correlated Solutions, Inc. (Irmo, SC, USA), using a subset size of 41 pixels. The obtained displacements were converted from pixels to millimeters by a scale factor (calibration image) in the post-processing stage. After the post-processing, the results of both the prisms and full-scale hybrid fiber reinforced prestressed beams were verified by comparing CMOD and deflections obtained from DIC analysis. The comparison of deflection measurements from linear variable displacement transducer and DIC results revealed that the displacements obtained from DIC analysis were accurate up to the ultimate load. In this study, the ultimate point corresponds to a $20 \%$ load drop from peak load in the post-peak range. 


\subsubsection{Evaluation of Crack Arresting Mechanisms of HFRC Prisms Using DIC}

The load-CMOD response of the HFRC prims was divided into four phases, as shown in Figure 5a for understanding the contributions of hybrid fibers in the crack arresting mechanism. Phase I starts from the application of load until it reaches the peak value. Phase II ranges from the peak load to the first load drop. Phase III ranges from the first load drop to the second peak load (due to the contribution of fibers). Finally, Phase IV starts from the second peak load and ends at a CMOD of $3.5 \mathrm{~mm}$. Due to elastic behavior, the toughness was not expected to change significantly in phase I. Toughness varied from $0.53 \times 10^{-3} \mathrm{kN}-\mathrm{mm}$ for HB00 to $1.58 \times 10^{-3} \mathrm{kN}-\mathrm{mm}$ for HB150 (Table 3) in phase I. Phase II represents the first load drop of the load-CMOD curve. The decrease in the load relative to the peak was reduced with increasing fiber content. In the case of HB150, strain hardening behavior was observed with no drop in the load after the first peak but with reduced stiffness. The toughness in phase II varied with an increase in fiber volume dosage. In HFRC prisms, the fibers started contributing to load resistance only after cracking the concrete matrix, i.e., after reaching the toughness of $3.14 \times 10^{-3} \mathrm{kN}-\mathrm{mm}$.

In phase III, even at higher CMOD values, no significant change was noted in the depth of crack propagation due to the active participation of fibers in crack arresting in the fracture process zone. A considerable strain redistribution across the cracked plane was observed because fibers are active in load redistribution. The second peak of load resistance was observed in phase III, and a full depth crack was formed. After that, a significant load drop can be observed in load-CMOD curves due to the pulling out of steel fibers and rupturing of macro-synthetic fibers [16].

However, the load resistance increased in phase III due to strain redistribution across the cracked plane due to the contribution of fibers (Table 3). In phase IV, a reduction in load-carrying capacity was observed due to the pulling out of steel fibers and rupturing of macro-synthetic fibers. The crack propagation at every stage of load-CMOD response was evaluated using DIC. From the DIC grid data of correlated images, the crack lengths were evaluated (Figure 5). At CMOD of $0.5 \mathrm{~mm}$, the crack length decreased with increasing fiber volume fraction. The strain redistribution across the newly formed surface is shown in Figure $5 \mathrm{a}-\mathrm{d}$. The reported contours are strain values in the horizontal direction $\left(\varepsilon_{x x}\right)$ at different critical points on the load-CMOD curve. The reduction in strain values at a particular load level with the increase in fiber dosage clearly shows the role of fibers in load resistance. Thus, hybrid fiber addition enables significant tensile stress transfer between the shear cracks and improves the post-peak behavior under shear dominant loads.

\subsection{Shear Behavior of HFRC Prestressed Concrete Beams}

\subsubsection{Test Setup and Instrumentation Details}

The prestressed concrete beams of dimensions $150 \mathrm{~mm} \times 300 \mathrm{~mm} \times 1600 \mathrm{~mm}$ were cast in the precast manufacturing plant by the stress bench method [32]. Two prestressing strands of diameter $12.70 \mathrm{~mm}$, having a specified modulus of elasticity of $196 \mathrm{GPa}$, were used [46]. The strands were pre-tensioned up to 4000 micro-strain using a mono-strand hydraulic jack. The total prestressing force of $154.5 \mathrm{kN}$ was applied at an eccentricity of $100 \mathrm{~mm}$, which induces average compressive stress of $3.43 \mathrm{MPa}$. Strain gauges were used to monitor the applied strain in the prestressing strand. During the release of prestressing, the strain loss due to elastic shortening of concrete was 80 microstrain. The strand was located below the centroid of the concrete section with a constant eccentricity of $100 \mathrm{~mm}$. As per IS1343-2012, the transmission length of a seven-wire prestressing strand was 30 times the diameter of the strand from the end of the beam. The loading point was located at a distance of $700 \mathrm{~mm}$ from the end. Thus, the full development of strands can be achieved well before the loading point [47]. The compressive stress due to prestressing in the bottom fiber was $10.15 \mathrm{MPa}$, and the tensile stress in the top fiber of the beam was $3.28 \mathrm{MPa}$. 

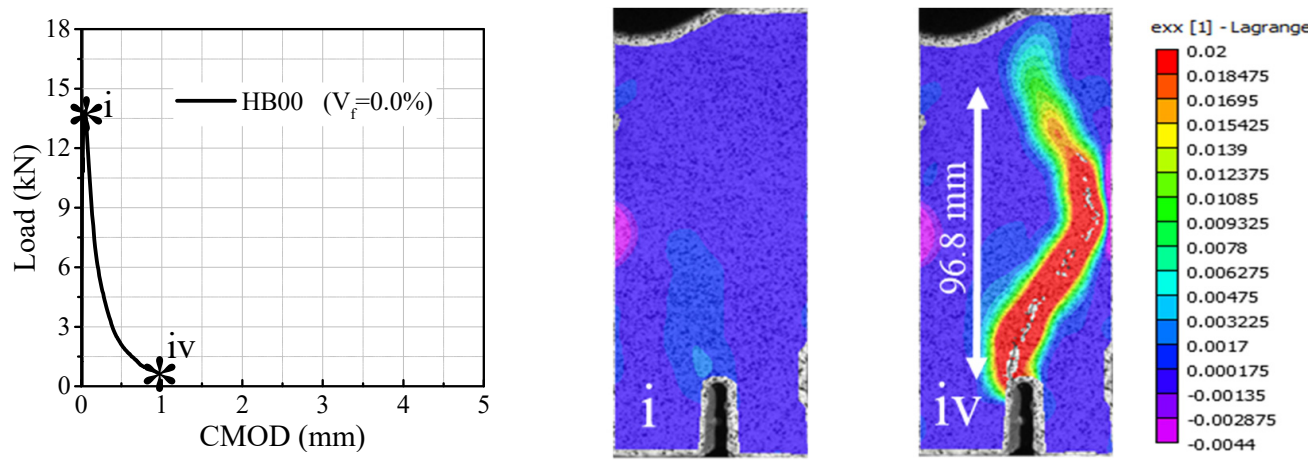

(a)
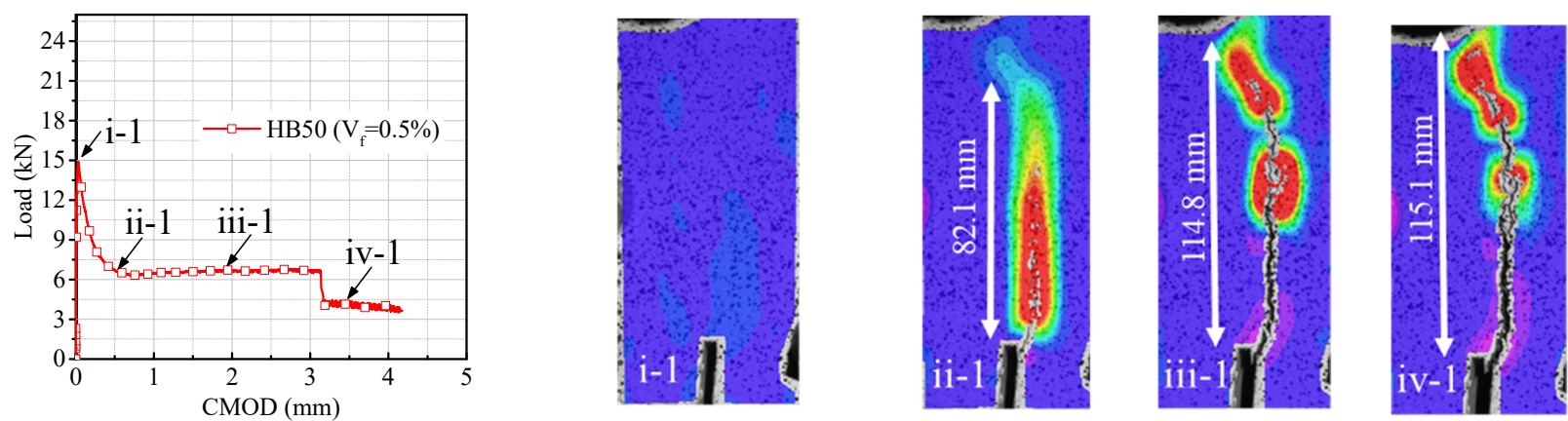

(b)
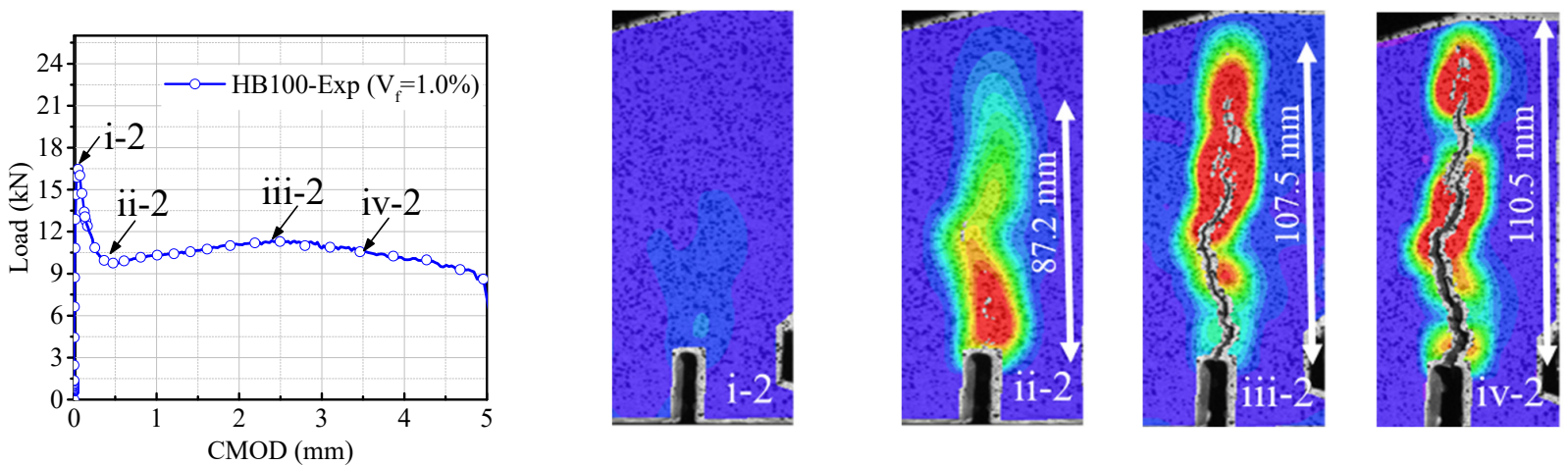

(c)
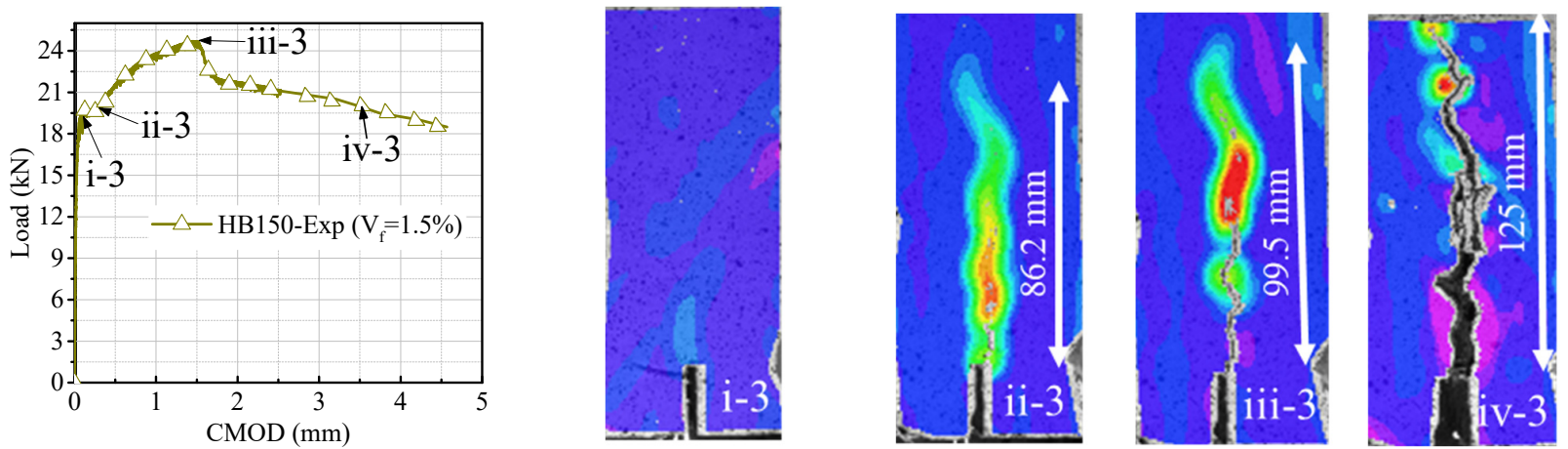

(d)

Figure 5. Load-CMOD curves with surface strain contour in x-direction of HB prisms: (a) HB00; (b) HB50; (c) HB100; (d) HB150. 
The effective cover of the beam was kept as $50 \mathrm{~mm}$ from the bottom of the beam, as shown in Figure 1. Stirrups of $8 \mathrm{~mm}$ diameter with a spacing of $75 \mathrm{~mm}$ were provided outside the test region to avoid failure, as shown in Figure 1. The prestressed beams were tested with a shear span to an effective depth ratio $(a / d)$ of $2.4[32,48,49]$. A shear span to depth ratio $(a / d)$ of 2.4 was chosen to avoid arch action and induce diagonal shear tension mode for understanding the effect of hybrid fibers on the shear behavior. The effect of fibers on the shear behavior of beams at a low $a / d$ ratio (less than 2 ) would be interesting, and this was discussed by Sagi et al. [25]. The load was applied in a displacement control mode at a rate of $0.025 \mathrm{~mm} / \mathrm{s}[24,34,50]$. The actuator load was transferred to beams through a rectangular plate of $70 \mathrm{~mm}$ width. This distribution plate was used to avoid local failure in compression due to concentrated load application in the compression zone. One linear variable displacement transducer (LVDT) was placed below the loading point and the other at the center of the shear span. Similarly, the strain in the prestressing strands was monitored by mounting strain gauges, and the locations of the attached gauges are shown in Figure 1.

\subsubsection{Load-Deflection Behavior}

The concrete mix used for the beams was reinforced with a hybrid combination of SF and PO fibers at different volume fractions, including 0.5\% (HB50), 1.0\% (HB100), and $1.5 \%$ (HB150). Two specimens were tested for each dosage to ensure the consistency of the results. The test configuration and DIC setup are shown in Figure $6 \mathrm{a}, \mathrm{b}$. The complete load-deflection response was compared at different key-points: (i) flexure crack denoted as " $a$ ", (ii) load at the formation of shear crack denoted as " $b$ ", (iii) peak load point denoted as " $\mathrm{c}$ ", and (iv) ultimate loading point denoted as " $\mathrm{d}$ " (80\% of peak load), as shown in Figure 6c. After the post-processing, the results of both the prisms and hybrid fiber reinforced prestressed beams were verified by comparing CMOD and deflections obtained from DIC analysis (Figure 6c,d).

\section{Control Specimen (HB00)}

In control beams (HB00), the flexural crack appeared at a load of $150.4 \mathrm{kN}$ in the tension zone below the loading point. On further loading, a shear crack was observed in the tension zone at a load of $178.3 \mathrm{kN}$ and a corresponding deflection of $2.95 \mathrm{~mm}$ below the loading point. After reaching the peak load, a sudden drop in the load-deflection curve was observed. Load drop was due to the formation of a major shear crack at an angle of $40^{\circ}$ to the longitudinal axis of the beam, which led to the loss in aggregate interlock. Thus, the failure mode for the control beam was identified as diagonal shear tension mode (DST).

\section{HB50 Beams}

HB50 beams were cast with concrete mix reinforced with $19.65 \mathrm{~kg} / \mathrm{m}^{3}\left(V_{f}=0.25 \%\right)$ of steel fibers and $2.27 \mathrm{~kg} / \mathrm{m}^{3}\left(V_{f}=0.25 \%\right)$ of macro-synthetic fibers. From the load-deflection responses of beams, insignificant increases in peak load (Figure 7a) and the post-peak strength were observed when compared to the control beam (HB00). However, the increase in post-peak stiffness due to the addition of fibers was considerable. To evaluate the postpeak response, the energy absorption capacities (EAC) of beams were measured as the ratios of the area under the load-deflection curves of the FRC beams to the area under the load-deflection curve of the control beams. The area under the load-deflection curve showed an up to $20 \%$ drop in peak load in the post-peak range. The EAC of HB50 beams varied from 5.3 to 6.2 times that of control beams (HB00), as stated in Table 4. The failure mode of the HB50 beam was identified as diagonal shear tension mode (DST). Thus, a low fiber dosage of $0.50 \%$ could not alter the brittle shear tension failure mode, although it significantly increased the energy absorption capacity. 


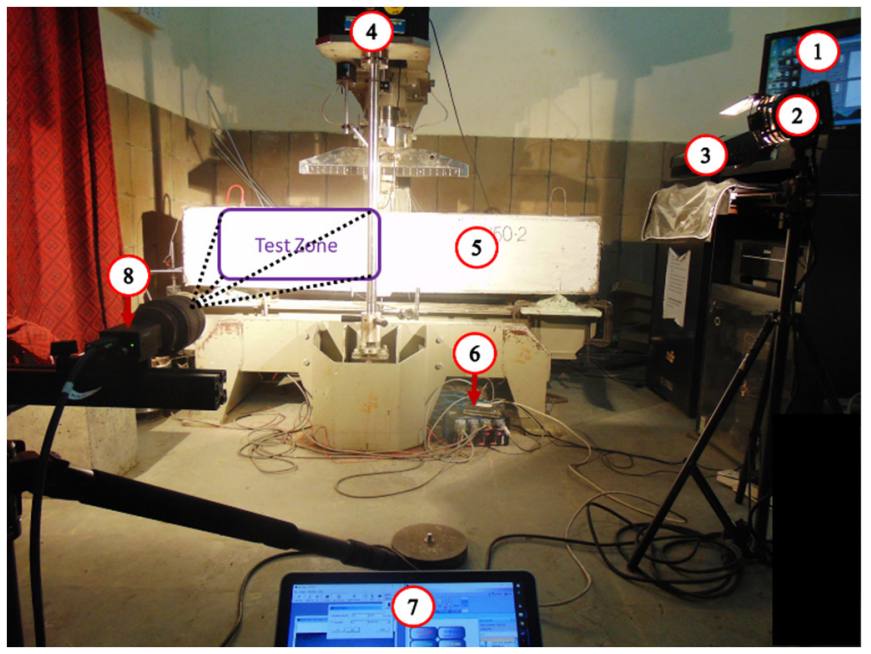

(a)

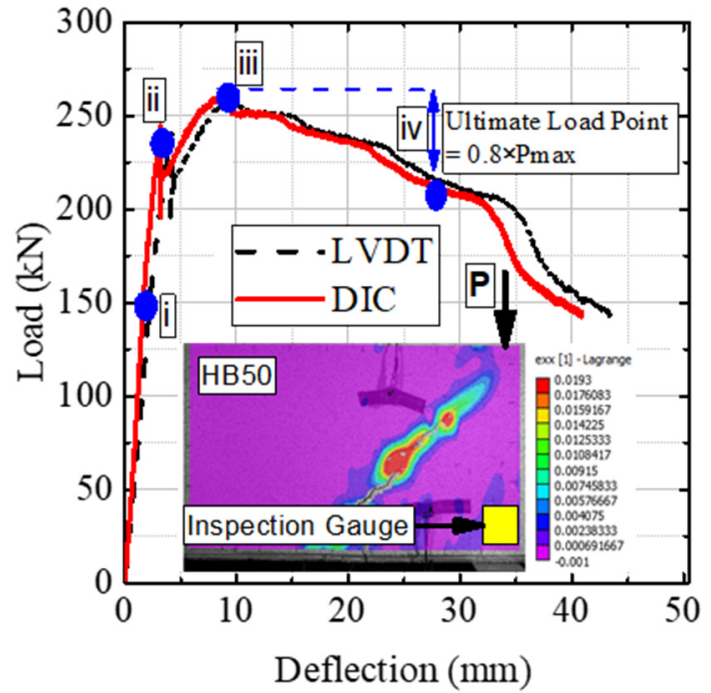

(c)

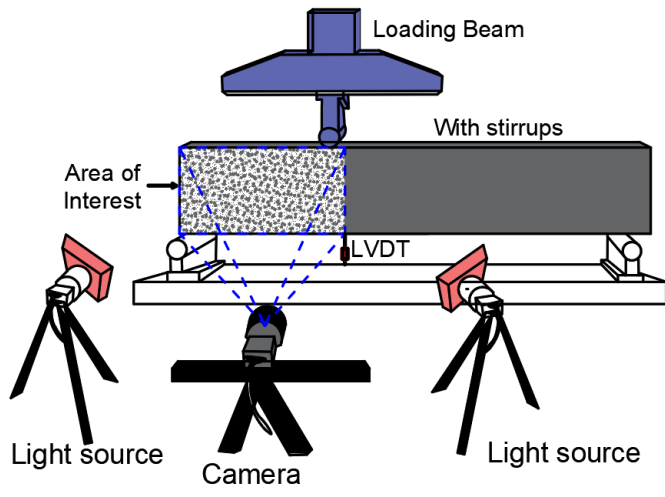

(b)

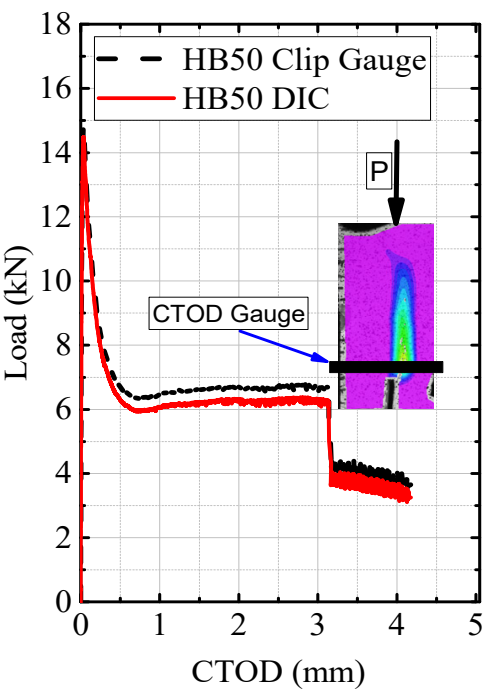

(d)

Figure 6. Experimental test setup for shear study: (a) Test setup. 1. Controller monitor. 2. The light source. 3. Controller. 4. FTM frame of $300 \mathrm{kN}$ capacity. 5. Test specimen. 6. Data Acquisition system (DAQ). 7. DAQ storage. 8. Digital image correlation camera. (b) Schematic view of instrumentation details of shear beams. (c) Calibration of DIC correlated deflections with LVDT deflections. $\mathrm{i}$ = flexure crack load point, $\mathrm{ii}=$ shear crack load point, $\mathrm{iii}=$ peak load point, $\mathrm{iv}=$ ultimate load point, (d) Calibration of DIC correlated CTOD with experimentally obtained CTOD.

\section{HB100 Beams}

HB100 beams were cast with concrete mix reinforced with $39.3 \mathrm{~kg} / \mathrm{m}^{3}$ of steel fibers $\left(V_{f}=0.5 \%\right)$ and $4.55 \mathrm{~kg} / \mathrm{m}^{3}\left(V_{f}=0.5 \%\right)$ of macro-synthetic fibers. Thus, the total volume fraction of fibers corresponded to $1 \%$ in HB100 beams. Considerable improvements in peak load carrying capacity and EAC were observed due to $1 \%$ fiber addition (Figure $7 \mathrm{~b}$ ). No difference in load-deflection behavior until cracking was observed between the control and high-fiber-dosage beams (HB100) (Figure 7b). Thus, as expected, the fibers are activated and effectively contribute to the load-carrying capacity only after the initiation of cracks. The EAC of the HB100 beam was significantly increased compared to that of control beams (Table 4). The shear crack angle of the HB100 beams was in the range of $35^{\circ}$ to $40^{\circ}$ with respect to the beam's longitudinal axis. Though energy absorption increased significantly, the failure mode did not change even with a $1.0 \%$ fiber dosage. This was due to the strain-softening response of fiber reinforced concrete, which can be witnessed by observing 
Figure $5 \mathrm{c}$. Even with a larger crack opening $(\mathrm{CMOD}=3 \mathrm{~mm})$, the strain redistribution across the crack can be observed. This resulted in a higher energy absorption capacity, and the ductility influenced the failure mode.

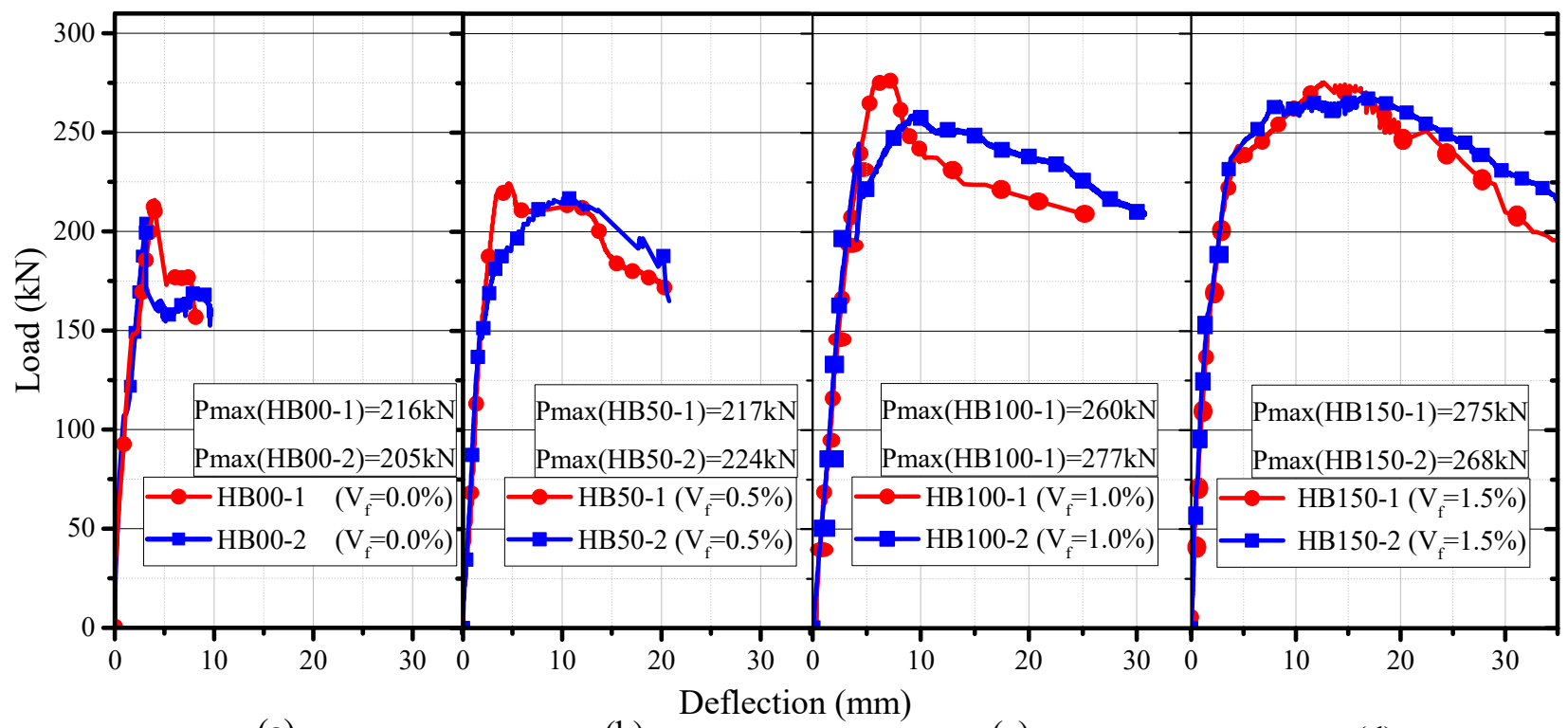

(a)

(b)

(c)

(d)

Figure 7. Load-deflection responses of HFRPC: (a) HB00; (b) HB50; (c) HB100; (d) HB150 beams.

Table 4. Summary of experimental results on beams.

\begin{tabular}{|c|c|c|c|c|c|c|c|}
\hline & НВ00-1 & HB50-1 & HB50-2 & HB100-1 & HB100-2 & HB150-1 & HB150-2 \\
\hline Flexure Cracking Load $(\mathrm{kN})$ & 150.4 & 145.8 & 143.5 & 150.4 & 150.8 & 150.9 & 153.7 \\
\hline $\begin{array}{c}\text { Deflection at Flexure Cracking } \\
\text { Load }(\mathrm{mm})\end{array}$ & 2.30 & 1.51 & 1.65 & 2.26 & 2.20 & 1.65 & 1.73 \\
\hline Shear Crack Load (kN) & 178.3 & 148.5 & 150.3 & 204.8 & 207.1 & 217.8 & 153.7 \\
\hline Deflection at Shear Crack Load (mm) & 2.96 & 1.70 & 1.73 & 3.30 & 3.11 & 1.65 & 1.73 \\
\hline Peak Load $(\mathrm{kN})$ & 215.9 & 216.9 & 224.4 & 260.6 & 276.9 & 275.5 & 268.1 \\
\hline Deflection at Peak Load (mm) & 4.01 & 9.61 & 4.77 & 9.66 & 6.79 & 13.35 & 16.65 \\
\hline Ultimate Load $(0.8 \times$ Peak Load $)(\mathrm{kN})$ & 172.7 & 173.5 & 179.6 & 208.5 & 221.5 & 220.4 & 214.57 \\
\hline Deflection at Ultimate Load (mm) & 5.19 & 20.80 & 17.74 & 30.71 & 12.72 & 31.05 & 35.52 \\
\hline $\begin{array}{c}\% \text { increase in peak load compared to } \\
\text { HB00, } \Delta \mathrm{P}(\%)\end{array}$ & 0 & 0.5 & 3.9 & 20.7 & 28.3 & 27.6 & 24.2 \\
\hline $\begin{array}{l}\text { Post-peak stiffness in load-deflection } \\
\text { curve from peak load to ultimate load, } \\
\qquad \mathrm{K}^{\prime}(\mathrm{kN} / \mathrm{mm})\end{array}$ & -36.6 & -3.9 & -3.5 & -2.5 & -9.3 & -3.1 & -2.8 \\
\hline $\begin{array}{c}\% \text { increase in post-peak stiffness, } \\
\Delta \mathrm{K}^{\prime}(\%)\end{array}$ & 0 & 89.4 & 90.4 & 93.2 & 74.6 & 91.5 & 92.3 \\
\hline $\begin{array}{l}\text { Energy absorption capacity, } \\
\text { EAC (Joules) }\end{array}$ & 643 & 3931 & 3371 & 6828 & 3667 & 7862 & 8509 \\
\hline$\Delta \mathrm{EAC}=\frac{\mathrm{EAC}}{\mathrm{EAC}_{\mathrm{c}}}$ & 1 & 6.1 & 5.3 & 10.6 & 6.0 & 12.2 & 13.2 \\
\hline Crack failure angle, $\theta^{\circ}$ & $40.8^{\circ}$ & $42.8^{\circ}$ & $39.2^{\circ}$ & $35.9^{\circ}$ & $40.4^{\circ}$ & $59.3^{\circ}$ & $56.7^{\circ}$ \\
\hline Failure Mode & DST & DST & DST & DST & DST & DST & DST \\
\hline
\end{tabular}




\section{HB150 Beams}

HB150 beams were cast with concrete mix reinforced with $58.58 \mathrm{~kg} / \mathrm{m}^{3}$ of steel fibers $\left(V_{f}=0.75 \%\right)$ and $6.83 \mathrm{~kg} / \mathrm{m}^{3}\left(V_{f}=0.75 \%\right)$ of macro-synthetic fibers. The load-deflection behavior of HB150 beams is shown in Figure 7c. Although there was no significant improvement in the peak load capacity of HB150 beams compared to HB100 beams, a considerable enhancement in ductility was observed. In HB150 beams, the first shear crack initiated at a load of $217 \mathrm{kN}$ (i.e., $80 \%$ to peak load). With a further increase in displacement, the same shear crack propagated towards the loading plate and the support along the prestressing strand. The beam failed due to discrete diagonal shear cracking in a diagonal shear tension (DST) mode. However, the critical shear crack angle increased from $35^{\circ}$ to $60^{\circ}$.

\subsubsection{Comparison of Normalized Load-Deflection Behavior of SF, MSF, and HB Beams}

The normalized load-displacement curves for the prestressed concrete beams reinforced with steel fibers, macro-synthetic fibers, and hybrid fibers are presented in Figure 8. Due to the variations in the compressive strength of concrete of various fiber-reinforced beams, the load parameter was normalized with respect to the parameter $f_{c m} b d[33,51]$. Here, the shear strength parameter is considered to be proportional to $f_{\mathrm{cm}}$. Note that this is just one of the possible normalization methods. In the case of SF and MSF beams, the peak load was reached at a deflection of $5 \mathrm{~mm}$. However, in the case of HB beams, the peak load was attained at a deflection of $10 \mathrm{~mm}$. Based on the load-deflection responses of steel, macro-synthetic, and hybrid fiber reinforced concrete beams and their failure modes, the performances of the hybrid fiber reinforced concrete beams were better in ductility and workability than both SF and MSF beams. A detailed discussion about the shear behavior of steel fiber reinforced prestressed concrete beams can be found in the previous work of the authors [32]. Similarly, detailed discussions such as the load-deflection response, failure mode, and capacity predictions of macro-synthetic fibers can be found in other studies [34]. Based on the experimental load-deflection behavior of FRPC beams (Figure 8), we observed that the peak load and deflection ductility increased significantly.

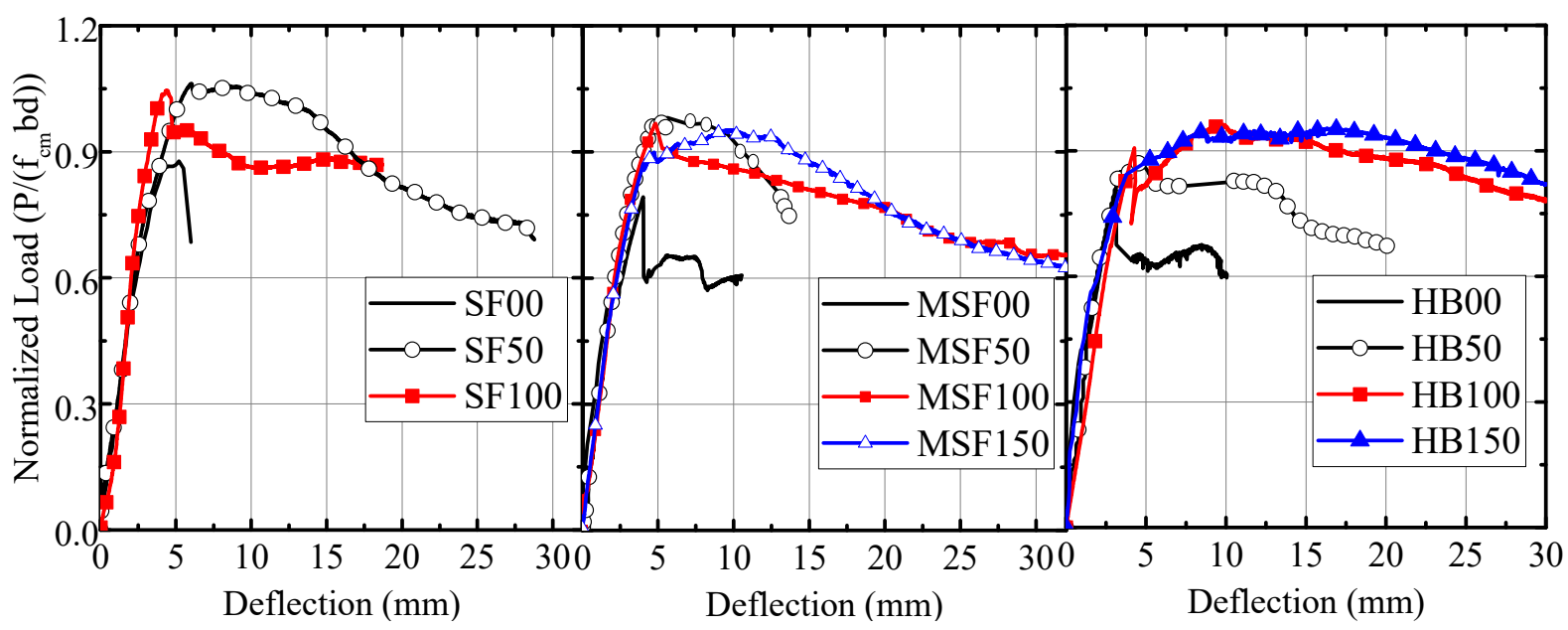

Figure 8. Normalized load-deflection curves of prestressed concrete beams reinforced with steel fibers (SF), macro-synthetic fibers (MSF), and hybrid fibers (HB).

\subsubsection{Analysis of Average Shear Strain and Angle of Principal Strain Using DIC}

Using post-processed data from DIC analysis, the average shear strain and angle of principal strains were calculated by installing gauge or virtual gauges, as shown in Figure 9a. The measurement of the angle of principal strain is important since it is related to the shear transfer mechanisms. The angle of the principal strain was calculated using Equation (5) [52-54]. The angles $\theta_{1}$ and $\theta_{3}$ are with respect to the longitudinal axis, as shown in Figure 9a. Similarly, $d_{1}$ is the displacement, and $L_{1}$ is the distance between 
virtual gauges $G_{1}$ and $G_{2}$. The average shear strains $\left(\gamma_{x y}\right)$ were measured by installing four rectangular gauges $\left(G_{1}, G_{2}, G_{3}\right.$, and $\left.G_{4}\right)$ at the corners of the area of interest in test beams, as shown in Figure 9a. However, the shear strain values depend on the field of measurement and location of rectangular inspection gauges $\left(G_{1}\right.$ to $\left.G_{4}\right)$. In this experimental program, the inspection gauges were installed at the farthest corners of the test region to capture the entire shear crack. Similarly, the angle of principal strain was experimentally measured using Equation (5). $e_{x}$ and $e_{y}$ are the longitudinal and vertical strains measured using virtual gauges, as shown in Figure 9a.

$$
\begin{gathered}
\gamma_{x y}=\frac{\theta_{1}+\theta_{3}}{2}=\frac{\left(\frac{d_{1}}{L_{1}}+\frac{d_{2}}{L_{3}}\right)}{2} \\
\theta_{p s}=0.5 \tan ^{-1}\left(\frac{\gamma_{x y}}{e_{x}-e_{y}}\right)
\end{gathered}
$$

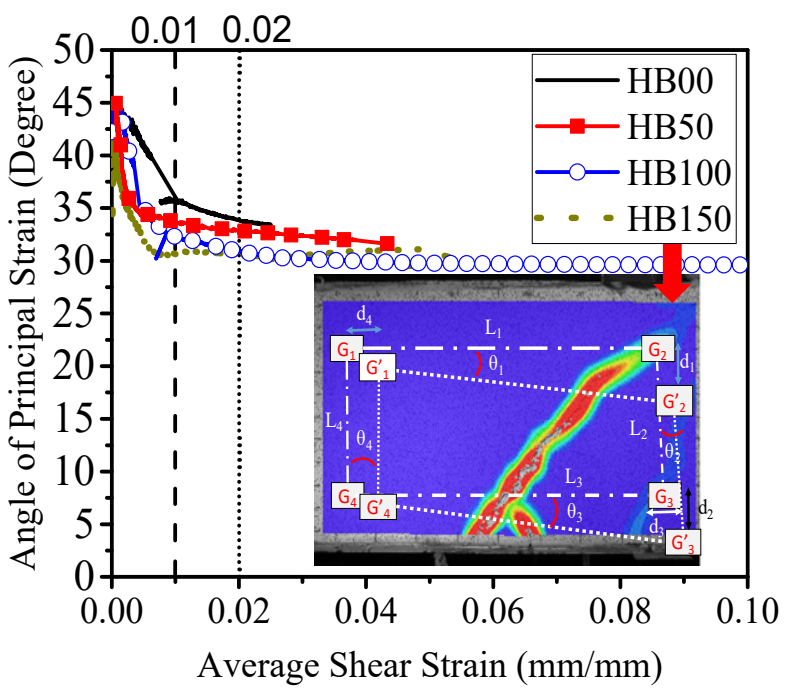

(a)

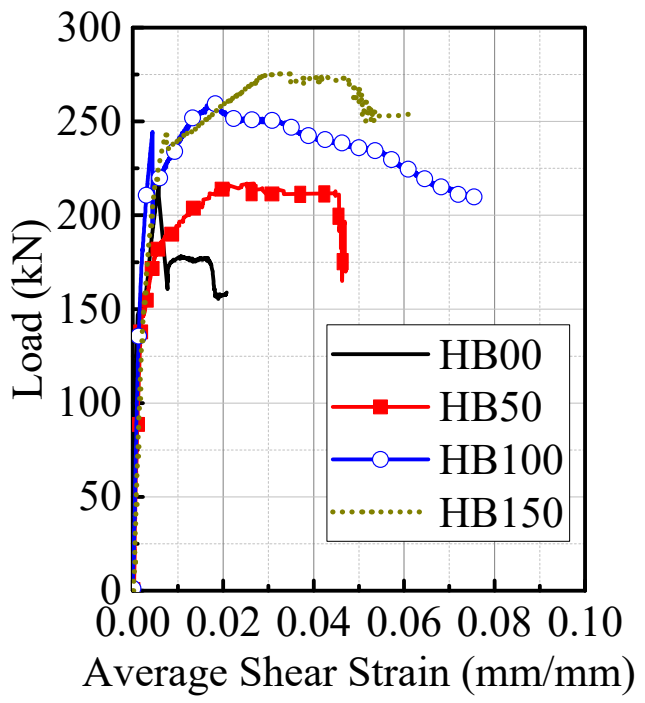

(b)

Figure 9. Load versus average shear strains and the angle of the average principal strain of HFRPC beams: (a) angle of principal strain vs. average shear strain; (b) load vs. average shear strain.

\subsubsection{Evaluation of Concrete Principal Strain at Different Load Levels}

From the DIC analysis, the average shear strains of each beam were calculated and reported in Figure 9b. Based on DIC measurements of average shear strains, the strain at peak load was around 0.02, as shown in Figure 9b. The average shear strain at failure load was varied from 0.05 to 0.08 for FRC beams. The angle of the principal strain of each specimen reduced from $45^{\circ}$ to $32^{\circ}$ and then stabilized at a strain of $0.01 \mathrm{~mm} / \mathrm{mm}$ in the range $30^{\circ}$ to $35^{\circ}$, as shown in Figure 9 a. With increased fiber dosage, the average shear strain angle reduced and remained constant after the shear strain of $0.02 \mathrm{~mm} / \mathrm{mm}$. Shear strain remained constant at 0.02 after the full depth crack formation in HFRPC beams.

The shear crack initiation in all beams was identified from the contours of the coefficient of correlation (sigma) from DIC analysis. The value of the coefficient of correlation changes significantly at the crack location, which can be used to identify the crack's exact location. For the HB00 beams, a sudden drop in load capacity was observed at the peak load point due to uncontrolled full depth shear crack formation. The loss in aggregate interlock can be identified from strain distribution along with the depth of beams (Figure 10). After the appearance of a full-depth shear crack, the tail of the crack progressively propagated towards the support along the prestressing strand, leading to final failure. Here, positive values of principal strain contours represent tensile strain, and negative values represent compressive strains. 


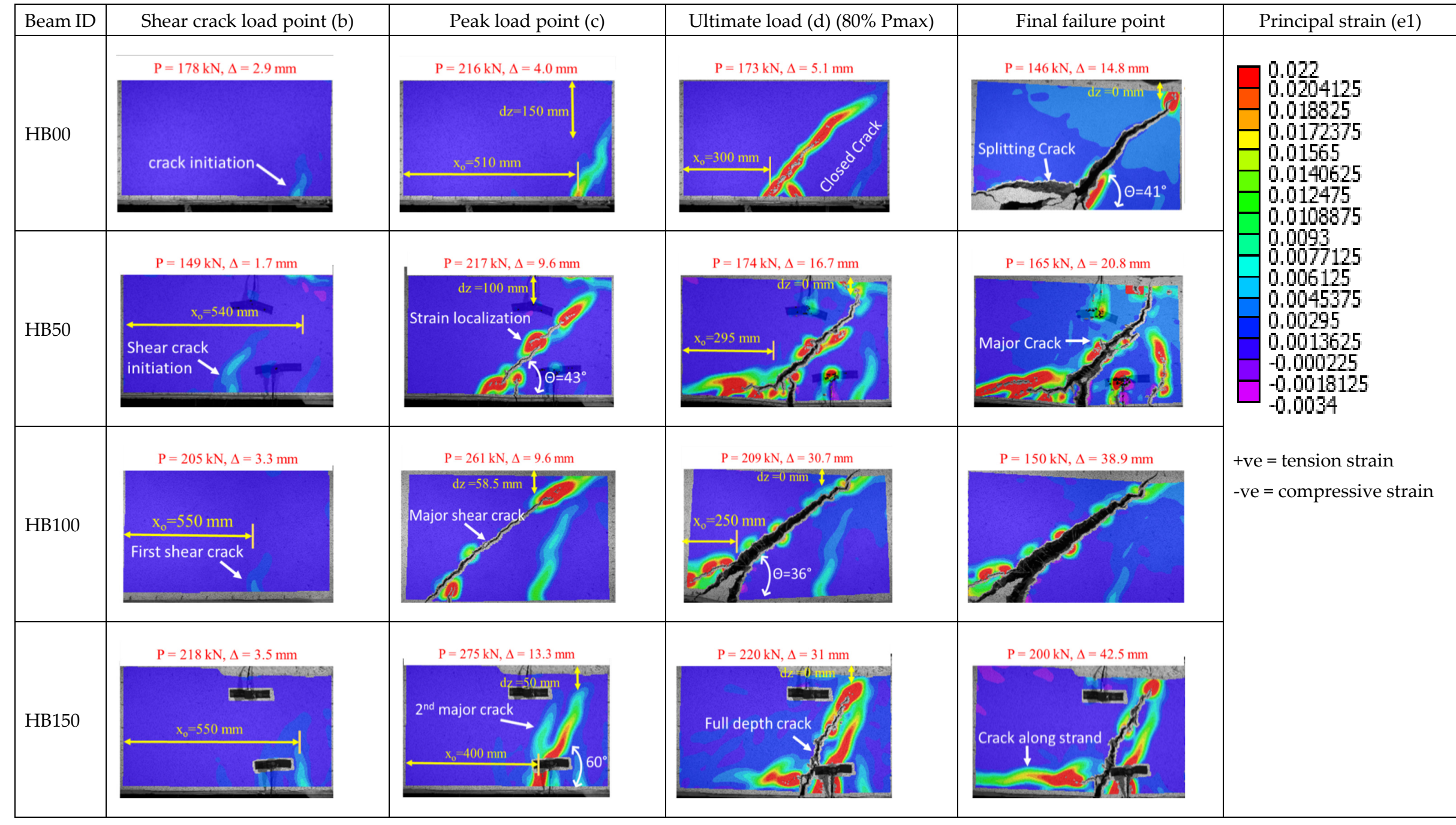

Figure 10. Strain variation in all test $\mathrm{HB}$ beams at various points of load-deflection curves. 
In the HB50 beams, a flexural crack initiated just below the loading point. After that, a shear crack formed at a distance of $295 \mathrm{~mm}$ away from the nearest support to the loading point. All these crack initiation points were identified using principal strain contours. With a further increase in the deflection of the beam, the same shear crack approached the loading beam. From DIC strain contours, it was observed that the strain was distributed uniformly across the crack at the peak load of $217 \mathrm{kN}$. The strain localization revealed the propagation path, as shown in Figure 10.

HB100 beams initially cracked from flexure. After initiating a major shear crack, the flexure cracks stopped propagating (Figure 10). The first shear crack in HB100 initiated at $82 \%$ of the peak load, i.e., $204.8 \mathrm{kN}$, which can be identified from principal strain contours. After the initiation of shear cracks, the nonlinearity in the load-deflection curve increased (Figure $7 \mathrm{~b}$ ). At a deflection of $3.98 \mathrm{~mm}$, a sudden drop in the load resistance occurred due to the formation of a major shear crack at an angle of $36^{\circ}$ (Figure 10). HB100 beams had major shear cracking at $65 \mathrm{kN}$. From the peak load point, the rate of load drop was constant up to a deflection of $30.7 \mathrm{~mm}$. Load resistance dropped continuously in the post-peak region due to the complete pull-out of fibers in the cracked surface of beams. Similarly, beams reinforced with regular shear reinforcements were tested by different authors [27,55-59], and the shear cracking load and crack angle variations were discussed.

Both the HB150 beams exhibited nonlinearity in load-deflection response after a load of $150 \mathrm{kN}$, as shown in principal strain plots (Figure 10). Due to the crack bridging action of fibers, secondary cracks did not propagate towards the compression zone. After reaching a load of $218 \mathrm{kN}$, the load-deflection curve exhibited nonlinearity, indicating the major crack (shear crack). The same shear crack propagated towards the loading point at higher displacements. Like HB50 and HB100 beams, HB150 beams also developed one full depth shear crack each at the peak load. In the post-peak region, a second major shear crack developed at $150 \mathrm{~mm}$ in HB150 above the tension side of the beam (Figure 10). At 80\% of peak load in the post-peak regime, a second major crack propagated from the tension side to the compression side. The increased applied displacement continuously progressed towards the left support, as shown in Figure 10.

The primary crack propagated towards the support, with a continuous distribution of strains. The progressive detachment of prestressing strands started at the shear crack initiation location close to the support. From the principal strain contours of all the test specimens, it can be observed that the uncracked concrete depth reduced with an increase in fiber dosage. This reduction indicates the complete strength of concrete was utilized in load resistance due to the improved tensile behavior of concrete from fiber addition.

Devalpura and Tadros [60] tested low relaxation prestressing strands and proposed models for stress-strain curves. Their test results showed that the yielding strain of the prestressing strand was about 10,000 microns. The tested HFRPC beams showed none of the prestressing strands of HFRPC beams yielded (reached a strain of about 10,000 microns) up to peak load. Thus, all the tested beams failed in the shear dominant mode (diagonal shear tension) without yielding the prestressing strand. However, the failure mode changed from brittle shear mode to a less brittle shear mode with higher energy absorption due to fiber addition. Likewise, the crack angle increased from $35^{\circ}$ to $60^{\circ}$ due to increased fiber dosage. An increase in crack angle also highlights the change in failure mode from brittle shear to less brittle shear (diagonal shear tension mode) with significant energy absorption.

\subsection{Measurement of Shear Parameters from DIC Analysis}

The accuracy of the deflection measurement from digital image correlation (DIC) was confirmed with measurements of linear variable displacement transducer (LVDT); see Figure 6a. After that, crack opening $\left(U_{w}\right)$ and crack slip $\left(U_{s}\right)$ data were extracted from DIC analysis. Critical parameters, such as crack profile, crack opening, crack slip, angle of principal strain, and average shear strains, were extracted from the processed DIC data. The $U_{w}$ and $U_{s}$ across the critical shear crack up to ultimate load are compared to understand the crack kinematic responses of fiber-reinforced prestressed concrete beams. Shear dilatancy 
is the volume change of the chosen area of interest when the beam is subjected to shear deformations. It is different from dilatancy, referred to in the context of confinement, where the volumetric expansion results from axial compression loads. The increases in crack width and slip are collectively termed here shear dilatancy. The effect of fiber dosage on the shear dilatancy of prestressed concrete beams is analyzed here. The effect of fiber dosage on the crack pattern, $U_{w}$, and $U_{s}$, along with the depth of the beam at a few critical points of load-deflections curves, is presented and discussed in the following section.

\subsubsection{Identification of Crack Pattern}

After post-processing, final cracks (the physical opening) were identified using the coefficient of correlation of the DIC grid data. The critical crack angle was extracted from the coordinates of the identified final crack by simple trigonometric formulation $(\tan (\theta)=d y / d x)$. The same angle was used to measure the crack kinematics $\left(U_{s}\right.$ and $\left.U_{w}\right)$. All the major and minor shear and flexure cracks were identified from the DIC grid data. According to Garnica [26], the major crack is defined as the one which propagates along with the depth from the tension to the compression zone. Minor cracks are defined as the ones which get arrested at the reinforcement level. This study considered the major cracks for the crack kinematic response (crack opening and crack slip). The test results of HFRPC beams revealed that the critical shear crack initiated in the range of 1.0 to 1.6 times $x_{0} / d$ at an angle of range $36^{\circ}$ to $60^{\circ}$, as shown in Figure 10. The ratio of $x_{0}$ to $\mathrm{d}$ increased from 1.2 to 1.6 for shear cracks in all the test beams except HB100. A change in the variation of $x_{0} / d$ reflects the change in failure from shear to flexure-shear dominated failure of HFRPC beams.

\subsubsection{Kinematics of Critical Shear Crack}

The crack opening $\left(U_{w}\right)$ and slip $\left(U_{s}\right)$ were measured along (tangential to) the crack and normal to it. A few common deflection points were considered for $U_{w}$ and $U_{s}$ measurements, along with the depth of HFRPC beams. A MATLAB program was developed to extract $U_{w}$ and $U_{s}$ from post-processed DIC grid data. To understand the overall responses of HFRPC beams to ultimate load, eight inspection or virtual gauges were installed across the critical shear crack of each HFRPC beam. The displacement along " $x$ " and " $y$ " directions was obtained from these gauges. The same displacements of individual gauges were transformed to parallel and perpendicular directions of the critical crack by simple transformation rules [26]. The differences in displacements of gauges (of individual layers) parallel and perpendicular to the crack are termed $U_{s}$ and $U_{w}$. In the measurement of the crack dilation response of beams, the crack angle $(\theta)$ plays an important role. Hence, the crack angle was measured from DIC grid data. From the failure modes of HFRPC beams (Figure 11a-d), it can be seen that the angles of major shear cracks were more or less identical across the depth. The schematic figure (Figure 11) represents the different critical cracks. In Figure 11, the flexural crack is marked with blue, and the critical shear crack is shown in red. 

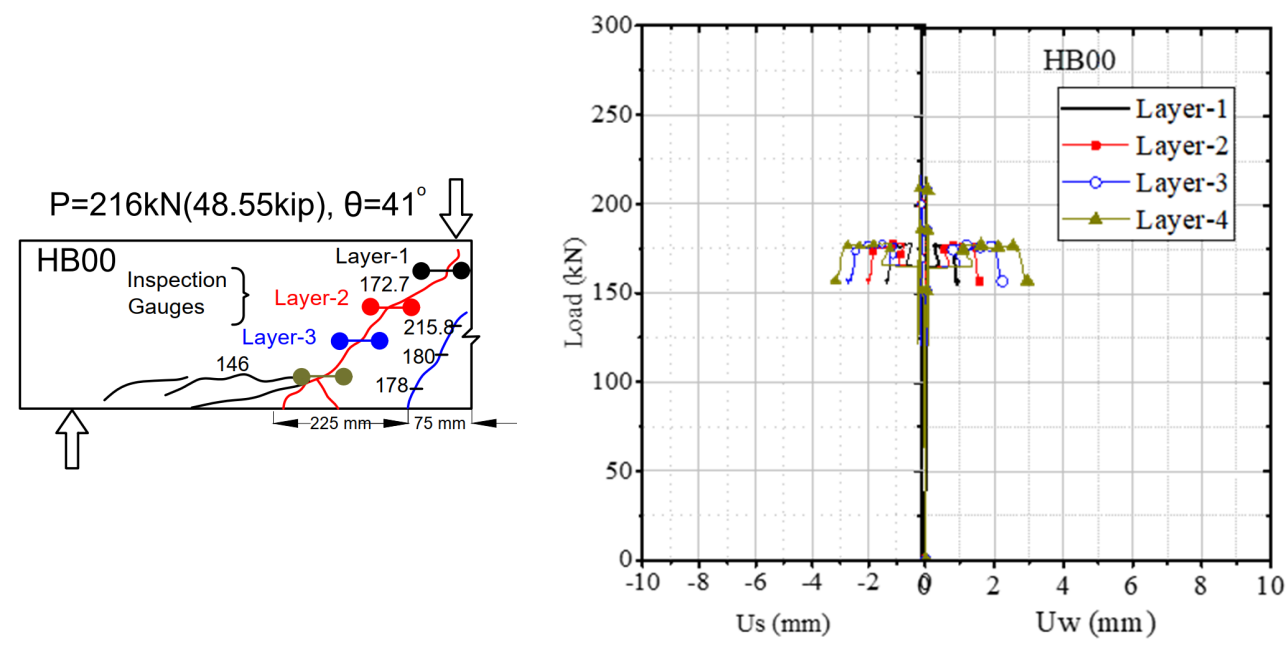

(a)

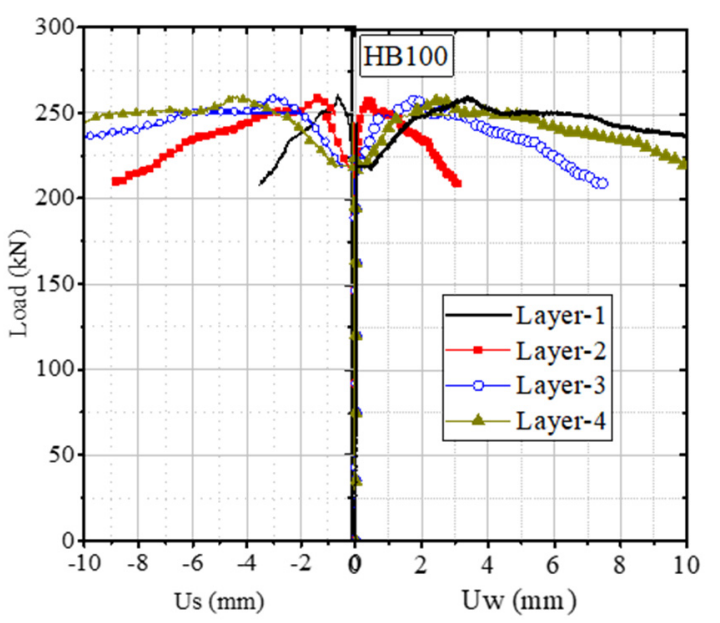

(c)

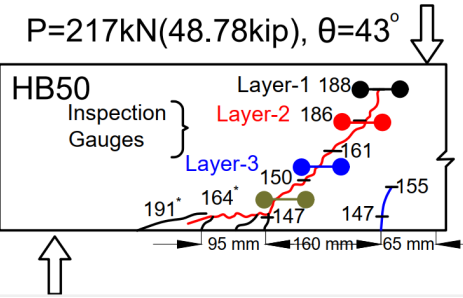

$P=275 \mathrm{kN}(61.82 \mathrm{kip}), \theta=60^{\circ} \Omega$

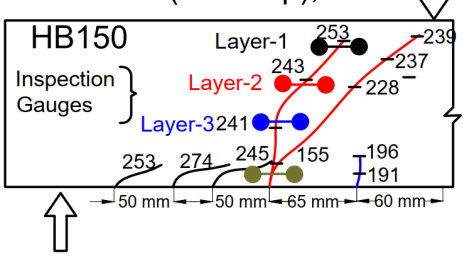

(b)

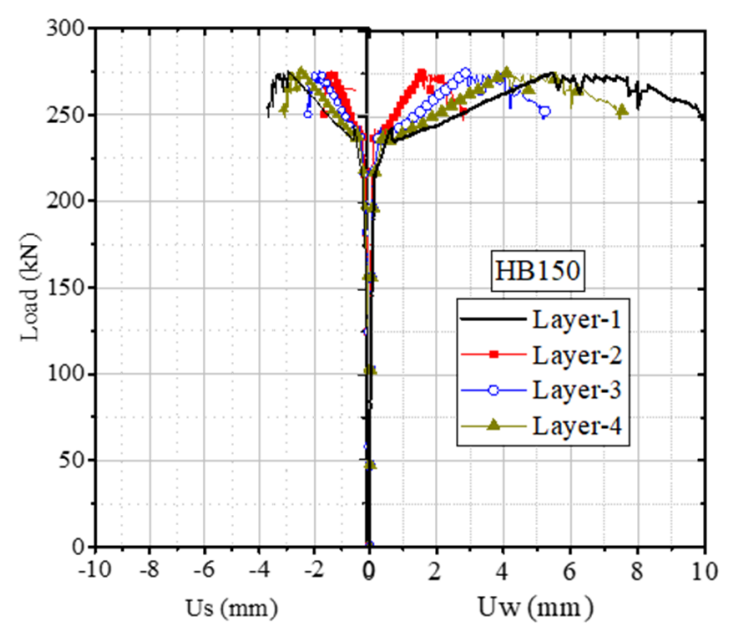

(d)

Figure 11. Failure mode and crack slip $\left(U_{s}\right)$ and crack opening $\left(U_{w}\right)$ with respect to load: (a) HB00, (b) HB50, $(\mathbf{c})$ HB100, $\left(\right.$ d) HB150, ${ }^{*}=$ post peak loads. 
The responses of $U_{w}$ and $U_{s}$ in different layers at an interval of $60 \mathrm{~mm}$ across the depth (Figure 11) were extracted from DIC grid data. The load versus crack opening and slip behavior is represented to understand the contributions of the hybrid fibers at all loading stages up to the ultimate load. Similarly, the schematics of the crack pattern (Figure 11) represent the load values at different crack depth levels for visualizing the crack initiation and its propagation during testing. For example, in the case of the HB50 beam at $188 \mathrm{kN}$ load, the average crack opening and slip was $1 \mathrm{~mm}$. Likewise, the complete responses of all HFRPC beams can be visualized. The crack opening and slip responses of layer 2, layer 3, and layer 4 were similar in all the specimens (Figure 11). To compare the critical shear crack behavior in terms of $U_{s}$ and $U_{w}$, the average measurements from all four layers for beams with different mixes are reported in Figure 12.

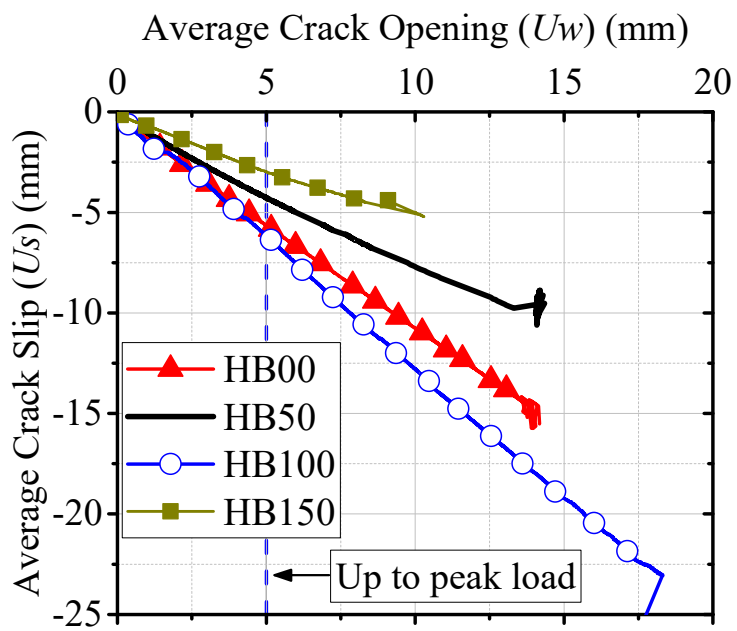

Figure 12. Average crack opening $\left(U_{w}\right)$ versus crack slip $\left(U_{s}\right)$ up to an ultimate load point.

All the tested specimens showed a continuous increase in the crack opening $\left(U_{w}\right)$ with progressive crack slip $\left(U_{s}\right)$ across the major shear crack. The increases in slip and opening of critical crack indicate that the crack slip reduced significantly with an increase in fiber volume fraction except for HB100 (Figure 12). The shear dilation response of hybrid fiber reinforced concrete beams was nearly linear up to the ultimate load (Figure 12). No effect of fiber was observed up to the initiation of critical shear crack. However, with an increase in fiber volume fraction in HFRPC beams, the crack slips reduced from 15 to $5 \mathrm{~mm}$ with an increase in fiber dosage up to ultimate load (Figure 12).

\subsubsection{Variations in Crack Opening and Crack Slip across the Depth of Beam}

To understand the progressive growth of crack opening with an increase in applied load, it is essential to observe the variations of $U_{s}$ and $U_{w}$ across the depth of the beam. To estimate the shear resistance due to aggregate interlock, the variations in $U_{s}$ and $U_{w}$ across the depth had to be studied. $U_{s}$ and $U_{w}$ were measured at an interval of $5 \mathrm{~mm}$ up to the ultimate load point. For this, a MATLAB program was written to extract $U_{w}$ and $U_{s}$ from the grid data (Figure 11). The crack propagation depth can be identified from the $U_{w}$ and $U_{s}$, along the depth of the beam (Figure 13). The crack opening at different deflections is shown in (Figure 13). For example, at $5 \mathrm{~mm}$ deflection, the critical crack depth reached almost $200 \mathrm{~mm}$ in the HB00 beam. At the same crack depth, the crack opening was in the range of 2 to $3 \mathrm{~mm}$. Similarly, in HB50 and HB150 beams, the crack propagation depths were identified as 100 and $75 \mathrm{~mm}$, respectively, at $5 \mathrm{~mm}$ deflection. Thus, the effect of fibers in controlling the crack arresting mechanism at a particular depth can be clearly understood for a specific deflection. The tip of the crack can be called a pivot point, which arrests the crack progression up to some extent, which can open up. Thus, a progressive 
shear stress transfer occurs in fiber-reinforced concrete beams. In Figure 13a-d, it is shown that the full depth crack developed at a deflection of $10 \mathrm{~mm}$.

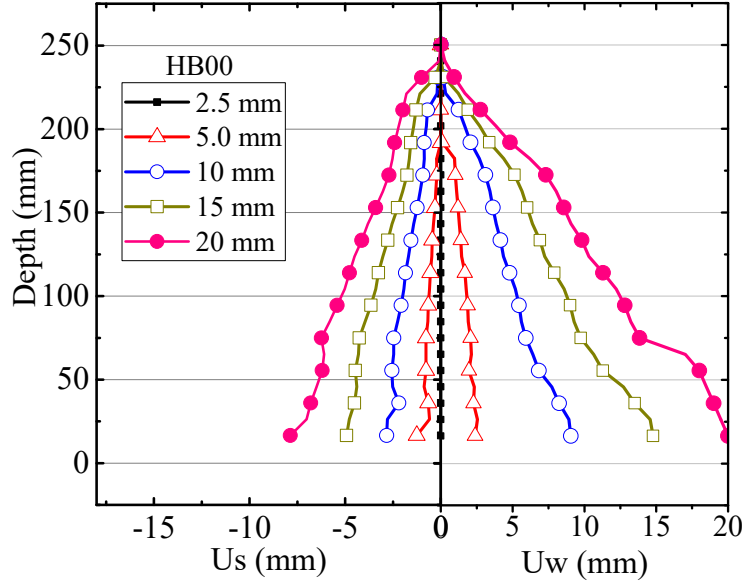

(a)

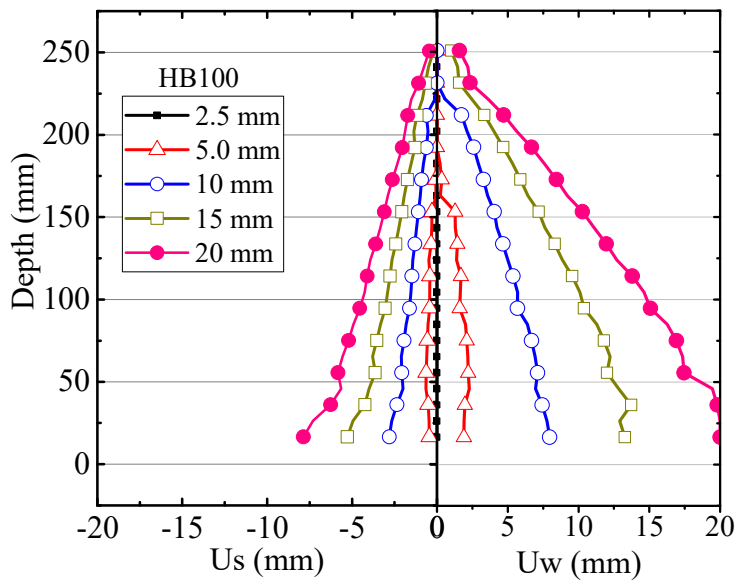

(c)

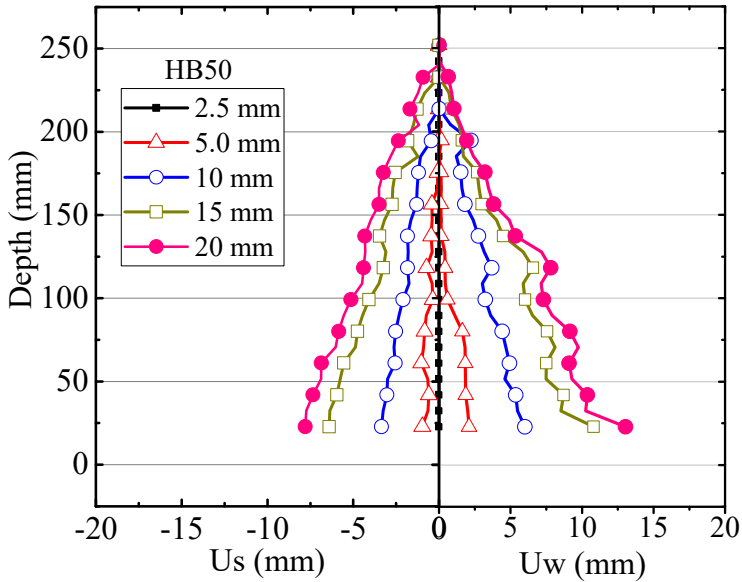

(b)

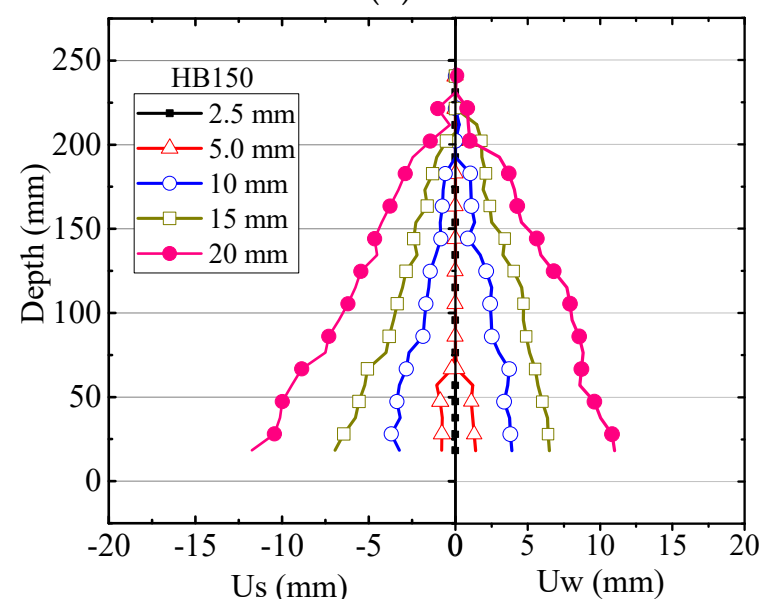

(d)

Figure 13. Crack opening $\left(U_{w}\right)$ and crack slip $\left(U_{s}\right)$ at different deflection points: (a) HB00 beam; (b) HB50 beam; (c) HB100 beam; (d) HB150 beam.

In the case of HB 150 beams, the maximum crack width at the deflection of $20 \mathrm{~mm}$ was $11.5 \mathrm{~mm}$, which was much less than that of the control (HB00) beam. This reduction in crack width shows that the addition of a higher dosage of fibers improves the crack arresting mechanisms, which enhances the ductility of the beams. Similarly, the crack slip response across the depth of beam represents the influence of hybrid fibers in controlling the crack slip response. At the deflection of $10 \mathrm{~mm}$, the slips across the beam depth were similar in all specimens (HB00, HB50, HB100, and HB150). The crack propagation length can also be estimated from the $U_{s}$ and $U_{w}$ responses of the beam. A few deflection points at an interval of $5 \mathrm{~mm}$ deflection up to $20 \mathrm{~mm}$ were considered to track the crack propagation. The crack slip responses were more or less similar in all the beams at corresponding deflection points (Figure 13). This shows that the hybrid fibers are more effective in arresting the crack opening than sliding/slipping.

\subsection{Shear Capacity Predictions Using Code Provisions}

The shear capacities of fiber-reinforced prestressed concrete beams were predicted using the provisions of RILEM [40] and Fib-MC2010 [61] code. The effect of fiber orientation $[62,63]$ on the structural response was not considered, and the distribution of fibers was considered uniform and randomly oriented. The FRC material was considered homo- 
geneous and isotropic. The average tensile strength of FRC can be obtained from RILEM recommendations, or the stress-crack opening relationship can be obtained from the inverse analysis $[7,39,64,65]$, and the same was used for shear capacity calculations. The shear resistance offered by the fiber-reinforced prestressed concrete beams included the uncracked concrete contribution, shear reinforcement contribution, fiber contribution, aggregate interlock, the vertical component of prestressing force, and dowel action due to longitudinal rebars [32]. The flexural tensile strength of concrete can be used to identify the fiber contribution along the shear crack direction. To identify the fibers' contribution in shear stress, a few authors assumed constant stress distribution along the crack $[38,50,66,67]$.

\subsubsection{RILEM Provisions}

The shear capacities ( $V_{\text {RILEM }}$ ) of HFRPC beams were calculated using RILEM [40] provisions. It consists of three shear resistance components: 1 . Resistance of member without shear reinforcement $\left(V_{c d}\right), 2$. Resistance due to discrete fibers $\left(V_{f d}\right), 3$. Stirrup contribution $\left(V_{w d}\right)$. The $V_{c d}$ equation includes the uncracked concrete contribution, dowel action, initial prestressing contribution, and aggregate interlock contributions. Similarly, $V_{f d}$ formulations include factors such as the depth factor and the flange of T-sections. In this study, the flange contribution factor $\left(k_{f}\right)$ was taken as 1 . Similarly, the other parameters, such as depth factor $\left(k_{l}\right)$, were calculated as per section details. The fiber contribution was estimated by using the residual resistance offered by fibers in tension at a CMOD of $3.5 \mathrm{~mm}$. The residual flexural tensile strengths of different fiber dosages depend on the compressive strength of the concrete, fiber type, and fiber dosage. However, the shear capacity of the tested HFRPC beams was evaluated by using the RILEM equations: Equations (6)-(12). The estimated shear capacity and test results of all beams were compared, and that showed that predictions were conservatively estimated. The $V_{E X P} / V_{\text {RILEM }}$ were $1.9,1.8,1.8$, and 1.6, respectively, as listed in Table 5.

$$
\begin{gathered}
V_{\text {RILEM }}=\left\{\left(0.12 k\left(100 \rho_{l} f_{c k}\right)^{\frac{1}{3}}+0.15\left(\frac{N_{s d}}{A_{c}}\right)\right)+\left(0.084 k_{f} k_{l} f_{R K, 4}\right)\right\} b d \\
k_{l}=k=1+\sqrt{\frac{200}{d}} \leq 2 \\
k_{f}=1+\mathrm{n}\left(\frac{h_{f}}{b_{w}}\right)\left(\frac{h_{f}}{d}\right) \leq 1.5 \\
n=\left(\frac{b_{f}-b_{w}}{h_{f}}\right) \leq 3 \\
\rho_{l}=\frac{A_{s}}{b d} \leq 0.002
\end{gathered}
$$

Table 5. Comparison of experimental results with RILEM and fib-MC2010 predictions.

\begin{tabular}{cccccccc}
\hline Beam ID & $V_{\text {EXP } \mathbf{~ k N}}$ & $\begin{array}{c}V_{c d} \\
\mathbf{~ k N}\end{array}$ & $\begin{array}{c}V_{f d} \\
\mathbf{~ k N}\end{array}$ & $\begin{array}{c}V_{\text {RILEM }} \\
\mathbf{k N}\end{array}$ & $V_{\text {EXP }} / V_{\text {RILEM }}$ & $V_{\text {fib-MC2010 }}$ & $V_{\text {EXP }} / V_{\text {fib-MC2010 }}$ \\
\hline HB00 & 215.9 & 109.0 & 0 & 109.0 & 1.9 & 136.8 & 1.5 \\
HB50 & 220.6 & 109.0 & 12.8 & 121.6 & 1.8 & 156.0 & 1.4 \\
HB100 & 268.7 & 109.0 & 34.0 & 142.8 & 1.8 & 165.8 & 1.6 \\
HB150 & 271.8 & 109.0 & 63.8 & 172.73 & 1.6 & 183.5 & 1.5 \\
\hline
\end{tabular}

\subsubsection{Fib-MC2010 Code Provisions for Shear Capacity}

In the fib-MC2010 code [61], all the shear contribution parameters from the shear capacity $\left(V_{R d, F}\right)$ formula were explicitly included. The parameters included in the shear capacity calculations were as follows:

1. Reinforcement ratio of longitudinal bars $\left(\rho_{l}\right)$. 
2. Size effect factor $(K)$.

3. Compressive strength of concrete $\left(f_{c k}\right)$.

4. Average stress $\left(\sigma_{\mathrm{cp}}\right)$ on the cross-section of concrete due to prestressing.

5. Ultimate residual tensile strength $\left(f_{\text {Ftuk }}\right)$ (Fracture parameter).

6. The characteristic value of tensile strength of concrete matrix $\left(f_{c t k}\right)$.

The fiber contribution in shear resistance was measured by residual flexural tensile strengths $\left(f_{R 1}\right.$ and $\left.f_{R 3}\right)$ at different CMODs of 1.5 and $3 \mathrm{~mm}$. The residual tensile capacities $\left(f_{\text {Ftuk }}\right)$ of FRC specimens were calculated based on experimental load-CMOD response. The partial safety factor in this calculation was considered as 1 . The equations used to measure the shear capacity are Equations (11)-(13):

$$
\begin{gathered}
V_{R d, F}=\left\{0.18 K\left[100 \rho_{l}\left(1+7.5 \frac{f_{\text {Ftuk }}}{f_{c t k}}\right)\left(f_{c m}-8\right)\right]^{1 / 3}+0.15\left(\frac{N_{s d}}{A_{c}}\right)\right\} b_{\mathrm{w}} d \\
f_{\text {Ftu }}\left(w_{\mathrm{u}}\right)=f_{\text {Fts }}-\frac{w_{\mathrm{u}}}{2.5}\left(0.45 f_{R 1}-0.5 f_{R 3}+0.2 f_{R 1}\right) \geq 0 \\
f_{c t m}=0.3 f_{c k}^{2 / 3}
\end{gathered}
$$

The obtained shear capacities of HFRPC beams are listed in Table 5. Due to the increase in the fiber dosage, both compressive and tensile strengths of concrete increased. Its influence was included in the RILEM calculation in the $V_{c d}$ term. Similarly, in the FibMC2010 provision, the influence of compressive strength is included in $V_{R d, F}$ term. From this limited experimental study on hybrid fiber reinforced prestressed concrete beams, the experimental shear capacity to theoretically calculate shear capacity varied in the range of 1.4 to 1.6. It shows that with an increase in fiber volume fraction, the shear capacity of the beam increased, as listed in Table 5. The predicted shear capacity and experimental measurement comparisons of fib-MC2010 and RILEM provisions show that the fib-MC2010 predictions were closer to the experimental results than the RILEM, as detailed in Table 5.

\section{Scope for Further Work}

Only limited tests were carried out in this study. The effects of different fibers (steel, macro-synthetic, and hybrid combinations) on the behavior of deep prestressed concrete beams at an $a / d$ ration lesser than 2.4 would be exciting to investigate. The use of the DIC technique can help in the pressure bulb or compression strut formation in deep beams, which can be used for the improved idealization of strut formation in design calculations. The effect of fiber dosage and fiber orientation factor on material behavior and structural behavior can also be considered in future work. Similarly, analyzing the shear carrying capacities of individual components of concrete, stirrups, fibers, aggregate interlock, and dowel actions using DIC measurements will be interesting and are within the scope of further work.

\section{Conclusions}

Structural tests on prestressed concrete beams were conducted to understand the influences of different volume fractions $\left(V_{f}=0 \%, 0.5 \%, 1.0 \%\right.$, and $\left.1.5 \%\right)$ of hybrid fibers on ductility, failure mode, and kinematics of the critical shear crack until failure. From the limited test results presented in this study, the following conclusions can be made:

- Fracture test results of the HFRC prism specimens showed an extended softening response compared to control specimens. Similarly, the residual flexural tensile strengths of hybrid fiber reinforced concrete compared to control concrete were 3.2, 4.7, and 10.35 times for HB50, HB100, and HB150 beams. The measurement of the residual strength of HFRC is critical for shear capacity calculations.

- The comparison of the load-deflection responses of steel, macro-synthetic, and hybrid fiber-reinforced beams shows that the performance of hybrid FRC beams was high. They had good ductility due to their better workability in the fresh state. 
- $\quad$ All the tested beams initially cracked from flexure. However, the final failure was because of a critical shear crack forming at an angle of $36^{\circ}-60^{\circ}$ to the longitudinal axis of the member. The failure mode changed from brittle shear to less brittle flexure-shear with an increase in fiber dosage.

- With an increase in fiber volume fraction in HFRPC beams, the crack opening and crack propagation depth in prestressed beams reduced at any specific load point, indicating effective crack bridging action.

- Only a marginal influence of hybrid fibers was observed on the dilatancy behavior up to the peak load. However, hybrid fibers significantly influenced the shear dilatancy response in the post-peak regime from peak load until final failure.

- The experimental to shear capacity predictions using RILEM recommendations vary from 1.6 to 2. However, fib-MC2010 code predictions are 1.5 times those of experimental results. Comparisons indicate that predictions using RILEM are more conservative than the fib-MC2010 provisions.

Author Contributions: C.L., A.B.B., S.S.P., and A.S. designed the test matrix. C.L. performed the experiments and wrote the paper. A.B.B., S.S.P., and A.S. reviewed the paper. All authors have read and agreed to the published version of the manuscript.

Funding: "Utchattar Avishkar Yojana (UAY) Scheme, Government of India through Grant No: YSS/2015/000677" by the Ministry of Human Resources Development, Department of Science and Technology; and the Prime Minister Research Fellowship—India, Project Number CE19RESCH11007.

Institutional Review Board Statement: Not applicable.

Informed Consent Statement: Not applicable.

Data Availability Statement: The data presented in this study are available within the manuscript.

Conflicts of Interest: The authors declare no conflict of interest.

\section{Notations}

$\begin{array}{ll}A_{\text {lig }} & = \\ A_{S} & = \\ b^{\prime} & = \\ b & = \\ b_{f} & = \\ b_{w} & = \\ C M O D_{C} & = \\ D & = \\ d_{1} & = \\ d_{2} & = \\ E c & = \\ e_{x} & = \\ e_{y} & = \\ \text { EAC } & = \\ \text { EACc } & = \\ f_{c}{ }^{\prime} & = \\ f_{c t k} & = \\ f_{c m} & = \\ f_{F t u} & = \\ f_{c t m} & = \\ f_{\text {fctm } f l} & =\end{array}$

Area of the ligament $(b \times h)$

$\left(\mathrm{mm}^{2}\right)$

Area of the tension reinforcement extending not less than ' $d+$ anchorage length' beyond the section considered

Width of the prism specimen

Width of the prestressed concrete beam

$(\mathrm{mm})$

Width of the flange

Minimum width of the section over the effective depth

$(\mathrm{mm})$

Crack mouth opening displacement at the time of rupture

$(\mathrm{mm})$

$(\mathrm{mm})$

The effective depth of the prestressed concrete beam

$(\mathrm{mm})$

Vertical displacement of virtual gauge $G_{2}-G_{2}^{\prime}$ in DIC

$(\mathrm{mm})$

Vertical displacement of virtual gauge $G_{3}-G_{3}^{\prime}$ in DIC

$(\mathrm{mm})$

Modulus of elasticity of concrete

(mm)

Strain in $\mathrm{x}$-direction $\left(\Delta L_{3} / L_{3}\right)$

$(\mathrm{MPa})$

Strain in $\mathrm{x}$-direction $\left(\Delta L_{4} / L_{4}\right)$

The energy absorption capacity of prestressed concrete beam

$(\mathrm{mm} / \mathrm{mm})$

$(\mathrm{mm} / \mathrm{mm})$

The energy absorption capacity of the prestressed concrete control beam

(Joule)

Average cylinder compressive strength

(Joule)

(MPa)

Characteristic tensile strength of concrete

(MPa)

Average compressive strength of concrete

(MPa)

The ultimate residual tensile strength at $1.5 \mathrm{~mm}$ crack width

(MPa)

Mean axial tensile strength of concrete

(MPa)

Mean flexural tensile strength

$(\mathrm{MPa})$ 


\begin{tabular}{|c|c|c|c|}
\hline$f_{R, j}$ & $=$ & $j$ th residual strength & $(\mathrm{MPa})$ \\
\hline$f_{R, 1}, f_{R, 4}$ & $=$ & Residual flexural strength of FRC at CMOD of $0.5 \mathrm{~mm}$ and $3.5 \mathrm{~mm}$ respectively & $(\mathrm{MPa})$ \\
\hline$g$ & $=$ & Gravitational acceleration (9.807) & $\left(\mathrm{m} / \mathrm{s}^{2}\right)$ \\
\hline$G_{f}$ & $=$ & Fracture energy of notched beams & $(\mathrm{N} / \mathrm{mm})$ \\
\hline$G_{f c}$ & $=$ & Fracture energy of notched control beam & $(\mathrm{N} / \mathrm{mm})$ \\
\hline$h_{s p}$ & $=$ & Distance between the tip of the notch to the top of cross-section & $(\mathrm{mm})$ \\
\hline$k$ & $=$ & Size effect factor $=1+\sqrt{\frac{200}{d}} \leq 2.0$ & \\
\hline$K_{h}$ & $=$ & Size factor & - \\
\hline$K_{f}$ & $=$ & Flange factor for considering flange effect in a T-section & - \\
\hline$L$ & $=$ & The total span of the notched beams for fracture test & $(\mathrm{mm})$ \\
\hline$L_{1}$ & $=$ & The horizontal displacement of virtual gauges G1-G2 in DIC & $(\mathrm{mm})$ \\
\hline$L_{3}$ & $=$ & The horizontal displacement of virtual gauges G4-G3 in DIC & $(\mathrm{mm})$ \\
\hline$m_{1}$ & $=$ & Mass of the specimen & $(\mathrm{kg})$ \\
\hline$m_{2}$ & $=$ & Mass of the jig not attached to the machine but placed on the specimen until rupture & $(\mathrm{kg})$ \\
\hline$N_{s d}$ & $=$ & Longitudinal force in the section due to loading or prestressing & $(\mathrm{N})$ \\
\hline$S$ & $=$ & Loading span of the beam used in fracture test & $(\mathrm{mm})$ \\
\hline$T_{f}$ & $=$ & The toughness of notched beams & $(\mathrm{kN}-\mathrm{mm})$ \\
\hline$V_{c d}$ & $=$ & Concrete contribution in total shear & $(\mathrm{kN})$ \\
\hline$V_{E X P}$ & $=$ & Experimental shear capacity & $(\mathrm{kN})$ \\
\hline$V_{f d}$ & $=$ & Fibers contribution in total shear & $(\mathrm{kN})$ \\
\hline$V_{\text {RILEM }}$ & $=$ & Predicted total shear capacity by RILEM approach & $(\mathrm{kN})$ \\
\hline$V_{w d}$ & $=$ & The contribution of shear reinforcement due to stirrups and inclined bars & $(\mathrm{kN})$ \\
\hline$V_{\text {fib }}$ & $=$ & Predicted total shear capacity by fib-MC2010 approach & $(\mathrm{kN})$ \\
\hline Wo & $=$ & The area below CMOD curve up to rupture of the specimen & $(\mathrm{N}-\mathrm{mm})$ \\
\hline$W_{1}$ & $=$ & Work done by the dead weight of the specimen and loading jig & $(\mathrm{N}-\mathrm{mm})$ \\
\hline$x_{0}$ & $=$ & Distance from support to crack in shear span & $(\mathrm{mm})$ \\
\hline$e_{y}$ & $=$ & Strain in $\mathrm{x}$-direction $\left(\Delta L_{4} / L_{4}\right)$ & $(\mathrm{mm} / \mathrm{mm})$ \\
\hline$\gamma_{x y}$ & $=$ & Shear strain in concrete & $(\mathrm{mm} / \mathrm{mm})$ \\
\hline$\theta_{p s}$ & $=$ & The angle of principal strain & (degrees) \\
\hline$\tau_{f d}$ & $=$ & The design value of the increased shear strain due to steel fibers & $(\mathrm{kN})$ \\
\hline
\end{tabular}

\section{References}

1. Kani, G. How Safe are Our Large Reinforced Concrete Beams? ACI J. Proc. 1967, 64, 128-141. [CrossRef]

2. Birrcher, D.B.; Tuchscherer, R.G.; Huizinga, M.; Bayrak, O. Minimum Web Reinforcement in Deep Beams. ACI Struct. J. 2013, 110, 297-306. [CrossRef]

3. Shahnewaz, M.; Alam, M.S. Improved Shear Equations for Steel Fiber-Reinforced Concrete Deep and Slender Beams. ACI Struct. J. 2014, 111, 851-860. [CrossRef]

4. Mihaylov, B.I.; Liu, J.; Simionopoulos, K.; Bentz, E.C.; Collins, M.P. Effect of Member Size and Tendon Layout on Shear Behavior of Post-Tensioned Beams. ACI Struct. J. 2019, 116, 265-274. [CrossRef]

5. Isojeh, B.; El-Zeghayar, M.; Vecchio, F.J. Fatigue Resistance of Steel Fiber-Reinforced Concrete Deep Beams. ACI Struct. J. 2017, 114, 1215-1226. [CrossRef]

6. Ahmad, S.; Bhargava, P. Shear Strength Models for Reinforced Concrete Slender Beams: A Comparative Study. Structures 2018, 16, 119-128. [CrossRef]

7. Bhosale, A.B.; Lakavath, C.; Prakash, S.S. Multi-linear tensile stress-crack width relationships for hybrid fibre reinforced concrete using inverse analysis and digital image correlation. Eng. Struct. 2020, 225, 111275. [CrossRef]

8. Karimipour, A.; Ghalehnovi, M. Comparison of the effect of the steel and polypropylene fibres on the flexural behaviour of recycled aggregate concrete beams. Structures 2021, 29, 129-146. [CrossRef]

9. Sharma, A.; Reddy, G.R.; Varshney, L.; Bharathkumar, H.; Vaze, K.K.; Ghosh, A.K.; Kushwaha, H.S.; Krishnamoorthy, T.S. Experimental investigations on mechanical and radiation shielding properties of hybrid lead-steel fiber reinforced concrete. Nucl. Eng. Des. 2009, 239, 1180-1185. [CrossRef]

10. Bošnjak, J.; Sharma, A.; Grauf, K. Mechanical Properties of Concrete with Steel and Polypropylene Fibres at Elevated Temperatures. Fibers 2019, 7, 9. [CrossRef]

11. Zhang, J.; Wang, Q.; Wang, Z. Properties of Polyvinyl Alcohol-Steel Hybrid Fiber-Reinforced Composite with High-Strength Cement Matrix. J. Mater. Civ. Eng. 2017, 29, 04017026. [CrossRef]

12. Padmarajaiah, S.K.; Ramaswamy, A. Flexural strength predictions of steel fiber reinforced high-strength concrete in fully/partially prestressed beam specimens. Cement Concrete Compos. 2004, 26, 275-290. [CrossRef]

13. Yoo, D.-Y.; Lee, J.-Y.; Shin, H.-O.; Yang, J.-M.; Yoon, Y.-S. Effects of blast furnace slag and steel fiber on the impact resistance of railway prestressed concrete sleepers. Cement Concrete Compos. 2019, 99, 151-164. [CrossRef] 
14. Vakili, S.E.; Homami, P.; Esfahani, M.R. Effect of fibers and hybrid fibers on the shear strength of lightweight concrete beams reinforced with GFRP bars. Structures 2019, 20, 290-297. [CrossRef]

15. Patil, G.M.; Suriya Prakash, S. Effect of Macrosynthetic and Hybrid Fibers on the Behavior of Square Concrete Columns Reinforced with GFRP Rebars under Axial Compression. J. Compos. Constr. 2021, 25, 04021053. [CrossRef]

16. Bhosale, A.; Rasheed, M.A.; Prakash, S.S.; Raju, G. A study on the efficiency of steel vs. synthetic vs. hybrid fibers on fracture behavior of concrete in flexure using acoustic emission. Constr. Build. Mater. 2019, 199, 256-268. [CrossRef]

17. Curosu, I.; Liebscher, M.; Mechtcherine, V.; Bellmann, C.; Michel, S. Tensile behavior of high-strength strain-hardening cementbased composites (HS-SHCC) made with high-performance polyethylene, aramid and PBO fibers. Cement Concrete Res. 2017, 98, 71-81. [CrossRef]

18. Bhowmik, S.; Ray, S. An experimental approach for characterization of fracture process zone in concrete. Eng. Fract. Mech. 2019, 211, 401-419. [CrossRef]

19. Das, S.; Aguayo, M.; Sant, G.; Mobasher, B.; Neithalath, N. Fracture process zone and tensile behavior of blended binders containing limestone powder. Cement Concrete Res. 2015, 73, 51-62. [CrossRef]

20. Abadel, A.; Abbas, H.; Almusallam, T.; Al-Salloum, Y.; Siddiqui, N. Mechanical properties of hybrid fibre-reinforced concreteAnalytical modelling and experimental behaviour. Mag. Concr. Res. 2016, 68, 823-843. [CrossRef]

21. Sivakumar, A.; Santhanam, M. Mechanical properties of high strength concrete reinforced with metallic and non-metallic fibres. Cement Concrete Compos. 2007, 29, 603-608. [CrossRef]

22. Shao, Y.; Billington, S.L. Impact of UHPC Tensile Behavior on Steel Reinforced UHPC Flexural Behavior. J. Struct. Eng. 2022, 148, 04021244. [CrossRef]

23. Witchukreangkrai, E.; Mutsuyoshi, H.; Takag, M.; De Silva, S. Evaluation of Shear Crack Width in Partially Prestressed Concrete Members. Proc. JCI 2006, 28, 823-828.

24. Joshi, S.S.; Thammishetti, N.; Prakash, S.S. Efficiency of steel and macro-synthetic structural fibers on the flexure-shear behaviour of prestressed concrete beams. Eng. Struct. 2018, 171, 47-55. [CrossRef]

25. Sagi, M.S.V.; Lakavath, C.; Prakash, S.S.; Sharma, A. Experimental Study on Evaluation of Replacing Minimum Web Reinforcement with Discrete Fibers in RC Deep Beams. Fibers 2021, 9, 73. [CrossRef]

26. Zarate Garnica, G. Analysis of Shear Transfer Mechanisms in Concrete Members without Shear Reinforcement Based on Kinematic Measurements; TU Delft: Delft, The Netherlands, 2018.

27. Gali, S.; Subramaniam, K.V.L. Shear Behavior of Slender and Non-Slender Steel Fiber-Reinforced Concrete Beams. ACI Struct. J. 2019, 116, 149-158. [CrossRef]

28. Torres, J.A.; Lantsoght, E.O. Influence of Fiber Content on Shear Capacity of Steel Fiber-Reinforced Concrete Beams. Fibers 2019, 7, 102. [CrossRef]

29. Abambres, M.; Lantsoght, E.O. ANN-Based Shear Capacity of Steel Fiber-Reinforced Concrete Beams without Stirrups. Fibers 2019, 7, 88. [CrossRef]

30. Lantsoght, E.O.L. Database of Shear Experiments on Steel Fiber Reinforced Concrete Beams without Stirrups. Materials 2019, 12, 917. [CrossRef]

31. Guerini, V.; Conforti, A.; Plizzari, G.; Kawashima, S. Influence of Steel and Macro-Synthetic Fibers on Concrete Properties. Fibers 2018, 6, 47. [CrossRef]

32. Lakavath, C.; Joshi, S.S.; Prakash, S.S. Investigation of the effect of steel fibers on the shear crack-opening and crack-slip behavior of prestressed concrete beams using digital image correlation. Eng. Struct. 2019, 193, 28-42. [CrossRef]

33. Tan, K.H.; Murugappan, K.; Paramasivam, P. Shear Behavior of Steel Fiber Reinforced Concrete Beams. ACI Struct. J. 1993, 90, 176-184. [CrossRef]

34. Lakavath, C.; Prakash, S.S.; Dirar, S. Experimental and numerical studies on shear behaviour of macro-synthetic fibre reinforced prestressed concrete beams. Constr. Build. Mater. 2021, 291, 123313. [CrossRef]

35. JCI-S-002-2003; Method of Test for Load-Displacement Curve of Fiber Reinforced Concrete by Use of Notched Beam. Japan Concrete Institute: Tokyo, Japan, 2003; pp. 3-8. Available online: https://www.jci-net.or.jp/j/jci/study/jci_standard/JCI-S-0012003-e.pdf (accessed on 13 January 2019).

36. Test Method for Metallic Fiber Concrete-Measuring the Flexural Tensile Strength (Limit of Proportionality (LOP), Residual); EN 14651:2005+A1:2007; British Standards Institution: London, UK, 2008.

37. Gustafsson, P.J.; Hillerborg, A. Sensitivity in Shear Strength of Longitudinally Reinforced Concrete Beams to Fracture Energy of Concrete. ACI Struct. J. 1988, 85, 286-294.

38. Foster, S.J.; Agarwal, A.; Amin, A. Design of steel fiber reinforced concrete beams for shear using inverse analysis for determination of residual tensile strength. Struct. Concr. 2018, 19, 129-140. [CrossRef]

39. Sahoo, S.; Lakavath, C.; Prakash, S.S. Experimental and Analytical Studies on Fracture Behavior of Fiber-Reinforced Structural Lightweight Aggregate Concrete. J. Mater. Civ. Eng. 2021, 33, 04021074. [CrossRef]

40. Rilem Tc 162-Tdf: Test and design methods for steel fibre reinforced concrete. Mater. Struct. 2003, 36, 560-567. [CrossRef]

41. JCI-S-001-2003; Method of Test for Fracture Energy of Concrete by Use of Notched Beam. Japan Concrete Institute: Tokyo, Japan, 2003; Volume 2, pp. 1-14.

42. Enfedaque, A.; Alberti, M.G.; Galvez, J. Influence of Fiber Distribution and Orientation in the Fracture Behavior of Polyolefin Fiber-Reinforced Concrete. Materials 2019, 12, 220. [CrossRef] 
43. Kang, S.-T.; Kim, J.-K. The relation between fiber orientation and tensile behavior in an Ultra High Performance Fiber Reinforced Cementitious Composites (UHPFRCC). Cement Concrete Res. 2011, 41, 1001-1014. [CrossRef]

44. Laranjeira, F.; Aguado, A.; Molins, C.; Grünewald, S.; Walraven, J.; Cavalaro, S. Framework to predict the orientation of fibers in FRC: A novel philosophy. Cement Concrete Res. 2012, 42, 752-768. [CrossRef]

45. Abrishambaf, A.; Pimentel, M.; Nunes, S. Influence of fibre orientation on the tensile behaviour of ultra-high performance fibre reinforced cementitious composites. Cement Concrete Res. 2017, 97, 28-40. [CrossRef]

46. Yang, T.; Dashlejeh, A.A.; Arabzadeh, A.; Hizaji, R. New model for prediction of ultimate load of prestressed RC deep beams. Structures 2020, 23, 509-517. [CrossRef]

47. Ramirez-Garcia, A.T.; Floyd, R.W.; Hale, W.M.; Martí-Vargas, J. Effect of concrete compressive strength on transfer length. Structures 2016, 5, 131-140. [CrossRef]

48. Kani, G.N.J. Basic Facts Concerning Shear Failure. ACI J. Proc. 1966, 63, 675-692. [CrossRef]

49. Juárez, C.; Valdez-Tamez, P.L.; Durán, A.; Sobolev, K. The diagonal tension behavior of fiber reinforced concrete beams. Cement Concrete Compos. 2007, 29, 402-408. [CrossRef]

50. Amin, A.; Foster, S. Shear strength of steel fibre reinforced concrete beams with stirrups. Eng. Struct. 2016, 111, 323-332. [CrossRef]

51. Perceka, W.; Liao, W.-C.; Wu, Y.-F. Shear Strength Prediction Equations and Experimental Study of High Strength Steel FiberReinforced Concrete Beams with Different Shear Span-to-Depth Ratios. Appl. Sci. 2019, 9, 4790. [CrossRef]

52. Hwang, J.-H.; Lee, D.H.; Ju, H.; Kim, K.S.; Kang, T.H.-K.; Pan, Z. Shear Deformation of Steel Fiber-Reinforced Prestressed Concrete Beams. Int. J. Concr. Struct. Mater. 2016, 10, 53-63. [CrossRef]

53. Tadepalli, P.R.; Hoffman, N.; Hsu, T.T.; Mo, Y.L. Steel Fiber Replacement of Mild Steel in Prestressed Concrete Beams (No. FHWA/TX09/0-5255-2); University of Houston: Houston, TX, USA, 2011.

54. Vecchio, F.J.; Collins, M.P. Modified Compression-Field Theory for Reinforced Concrete Elements Subjected To Shear. J. Am. Concr. Inst. 1986, 83, 219-231. [CrossRef]

55. Khan, M.A.; Ahmed, F.S. Effect of Web Reinforcement On Ultimate Strength Of Reinforced Concrete Deep Beams. ACI Struct. J. 1997, 94, 572-581.

56. Smith, K.N.; Vantsiotis, A.S. Shear Strength of Deep Beams. J. Am. Concr. Inst. 1982, 79, 201-213. [CrossRef]

57. Adebar, P.; Van Leeuwen, J. Side-Face Reinforcement for Flexural and Diagonal Cracking in Large Concrete Beams. ACI Struct. J. 1999, 96, 693-704. [CrossRef]

58. Susanto, T.; Ma, W.; Fang, W. Shear strength of high-strength concrete deep beams under Fatigue Loading. ACI Struct. J. 2000, 97, 572-580.

59. Sahoo, D.R.; Bhagat, S.; Reddy, T.C.V. Experimental study on shear-span to effective-depth ratio of steel fiber reinforced concrete T-beams. Mater. Struct. Constr. 2016, 49, 3815-3830. [CrossRef]

60. Devalapura, R.K.; Tadros, M.K. Stress-Strain Modeling of 270 ksi Low-Relaxation Prestressing Strands. PCI J. 1992, 37, 100-106. [CrossRef]

61. Model Code 2010-First Complete Draft-Volume 2: Model Code; Fédération Internationale du Béton (fib): Lausanne, Switzerland, 2010; Volume 56, ISBN 964-7445-88-1.

62. Alberti, M.; Enfedaque, A.; Gálvez, J. On the prediction of the orientation factor and fibre distribution of steel and macro-synthetic fibres for fibre-reinforced concrete. Cement Concrete Compos. 2017, 77, 29-48. [CrossRef]

63. Mudadu, A.; Tiberti, G.; Germano, F.; Plizzari, G.A.; Morbi, A. The effect of fiber orientation on the post-cracking behavior of steel fiber reinforced concrete under bending and uniaxial tensile tests. Cement Concrete Compos. 2018, 93, 274-288. [CrossRef]

64. Reddy, K.C.; Subramaniam, K. Analysis for multi-linear stress-crack opening cohesive relationship: Application to macro-synthetic fiber reinforced concrete. Eng. Fract. Mech. 2017, 169, 128-145. [CrossRef]

65. Stephen, S.J.; Raphael, B.; Gettu, R.; Jose, S. Determination of the tensile constitutive relations of fiber reinforced concrete using inverse analysis. Constr. Build. Mater. 2019, 195, 405-414. [CrossRef]

66. Kaufmann, W.; Amin, A.; Beck, A.; Lee, M. Shear transfer across cracks in steel fibre reinforced concrete. Eng. Struct. 2019, 186, 508-524. [CrossRef]

67. El-Helou, R.G.; Graybeal, B.A. Shear Behavior of Ultrahigh-Performance Concrete Pretensioned Bridge Girders. J. Struct. Eng. 2022, 148, 04022017. [CrossRef] 